\title{
Ethnic Scientific Communities and International Technology Diffusion
}

\author{
William Kerr* \\ Harvard Business School and MIT \\ This Draft: 15 September 2005 \\ First Draft: August 2004
}

\begin{abstract}
This study explores the importance of tacit knowledge transfer for international technology diffusion by examining ethnic scientific communities in the US and their ties to their home countries. US ethnic research communities are quantified by applying an ethnic-name database to individual patent records. International patent citations confirm knowledge diffuses through ethnic networks, and manufacturing output in foreign countries increases with an elasticity of approximately 0.3 to stronger scientific integration with the US frontier. To address reverse-causality concerns, reduced-form specifications exploit exogenous changes in US immigration quotas. Consistent with a model of sector reallocation, output growth in less developed economies is facilitated by employment gains, while more advanced economies experience sharper increases in labor productivity. The findings suggest tacit knowledge channels partly shape the effective technology frontiers of developing economies.
\end{abstract}

JEL Classification: F22, J44, J61, O31, O32, O33, O41, O57.

Key Words: Technology Transfer, Tacit Knowledge, Productivity, Patents, Innovation, Research and Development, Immigration, Networks.

\footnotetext{
*Comments are appreciated and can be sent to wkerr@hbs.edu. I am grateful to Daron Acemoglu for his mentoring throughout my graduate studies; to Dan Johnson and Brian Silverman for data assistance; and to George-Marios Angeletos, Josh Angrist, David Autor, Ricardo Caballero, Xavier Gabaix, Francesco Giavazzi, Michael Greenstone, Josh Lerner, Ashley Lester, Guido Lorenzoni, Byron Lutz, Philip Oreopoulos, Michale Piore, and Ivan Werning for advice on this project. This research is supported by the National Science Foundation and the MIT George Schultz Fund.
} 


\section{Introduction}

The adoption of new technologies and innovations is a primary engine for economic growth, improving worker productivity and spurring higher standards of living. Invention, however, is concentrated in advanced economies. OECD countries account for $83 \%$ of the world's R\&D expenditure and $98 \%$ of its patenting (OECD 2004). Even within the OECD, a disproportionate share of R\&D is undertaken in the US. Diffusion of new innovations from technologically leading nations to following economies is thus necessary for the economic development of poorer regions and the achievement of global prosperity.

Economic models often describe a worldwide technology frontier, where new ideas and innovations travel quickly to all countries. ${ }^{1} \quad$ Rapid diffusion may be a good approximation for industrialized economies, but many advances are either not available or not adopted in poorer countries. Case studies in the business sociology and economic history literatures suggest this poor adoption may result from inadequate access to the informal or practical knowledge that complements the codified details of new innovations. ${ }^{2}$ Be it between two people or two countries, knowledge transfer is much more complicated than sharing blueprints, process designs, or journal articles. Intellectual spillovers are often thought to be important for the formation of cities and high-tech clusters, and perhaps heterogeneous access to the tacit knowledge associated with new innovations shapes the effective technology sets of following countries. ${ }^{3,4}$

Recent research stresses the importance of ethnic scientific communities in frontier countries for conveying new technologies to their home countries. In surveys of Silicon Valley, $82 \%$ of Chinese and Indian immigrant scientists and engineers report exchanging technical information with their respective nations; 18\% further invest in business partnerships (Saxenian 2002a, 2002b). Studies of software off-shoring suggest $30 \%$ of India's systems workforce rotates through the US to obtain the tacit knowledge necessary for their work (Piore 2004). Moreover, some observers believe the success of India versus Mexico and other countries in this field derives in part from India's strong US entrepreneurial community. More generally, explorations of knowledge diffusion find countries with a common language have larger R\&D spillovers and international patent citation rates (e.g., Keller 2002b, Jaffe and Trajtenberg 1999).

\footnotetext{
${ }^{1}$ For example, Mankiw, Romer, and Weil (1992) and Heckscher-Ohlin trade theory. Recent descriptions of multiple technology frontiers instead build on geographic distances to major R\&D nations (e.g., Keller 2002b), the innovative efforts of trading partners (e.g., Grossman and Helpman 1991, Coe and Helpman 1995), or international patenting decisions (e.g., Eaton and Kortum 1999). Keller (2004) reviews the technology transfer literature.

${ }^{2} \mathrm{An}$ intuitive example is the construction of an atomic bomb. While the basic designs are available on the internet, efforts to stem nuclear weapons proliferation focus extensively on the scientists with the tacit knowledge necessary for implementation. Other examples are drawn from Lester and Piore (2004), Amsden (2001), Feinstein and Howe (1997), Kim (1997), and Lim (1999). Polanyi $(1958,1966)$ introduces tacit knowledge.

${ }^{3}$ Marshall (1890) and Jacobs (1970) describe the forces contributing to spatial agglomeration, while Dumais, Ellison, and Glaeser (1997) and Rosenthal and Strange (2003) provide more recent empirical tests.

${ }^{4}$ Other country-specific differences that inhibit adoption include barriers to technological investment, capitallabor or human-capital disparities, differences in the organization of production, and the appropriateness of technology. Representative papers in this literature are Parente and Prescott (1994), Atkinson and Stiglitz (1969), Nelson and Phelps (1966), Banerjee and Newman (1993), and Acemoglu and Zilibotti (2001), respectively.
} 
Ethnicity thus offers an observable channel for exploring whether and how international networks transmit the tacit knowledge of new inventions. The primary question this project addresses is whether a larger ethnic research community in the US improves technology diffusion to foreign countries of the same ethnicity. US research communities are quantified for ethnicities by applying an ethnic-name database to individual US patent records (e.g., identifies inventors with Chinese versus Hispanic names). These matched records describe the ethnic composition of US scientists and engineers with previously unavailable cross-sectional and longitudinal detail. These trends are joined with industry-level manufacturing data for foreign countries (e.g., Chinese computer research in the US is paired with China's computer industry) in an econometric framework that isolates the role of scientific integration by exploiting withinindustry variation. This approach affords a more structured characterization of ethnicity's role in the diffusion process; it further allows the outcomes of different ethnicities and industries to be contrasted.

To clarify this empirical methodology, the next section develops a theoretical model focusing on tacit knowledge and technology transfer. The model considers a technology follower that depends on the imitation of frontier innovations for technical progress in its manufacturing sector. In order to imitate these frontier technologies, however, scientists in the following country require tacit knowledge with respect to the frontier inventions. This tacit knowledge is acquired and transferred through the scientists of the following country's ethnicity who work in the frontier economy. The model thereby relates the technology follower's manufacturing output and productivity growth to its scientific integration with the technology leader. The primary estimating equations employed in this study are determined within this framework, and the conditions under which ordinary least squares estimations capture causal relationships are identified.

Section 3 then describes the ethnic patenting dataset constructed, and a first characterization of ethnicity's role in international knowledge transfer is undertaken through citation patterns. Foreign researchers are found to cite US researchers of their own ethnicity $50 \%$ more frequently than researchers of other ethnicities, even after controlling for detailed technology classes. A further examination divides the sample into different time lags from the filing dates of the cited US patents to the dates of the citing foreign patents. This analysis reveals that the own-ethnicity effect is most important during the first four to five years of the diffusion process.

While informative, citation patterns do not demonstrate that following countries realize economic benefits from better access to US innovations. To characterize foreign output and productivity realizations, the US ethnic patenting data are combined with industry-level manufacturing data for foreign countries in Section 4. Ethnic research communities are quantified at the industry-year level by aggregating individual patent records. Stringent fixed-effects estimations then test whether output increases in foreign countries as their respective ethnic research communities in the US develop. The specifications only exploit within-industry variation, and 
robustness checks further consider human-capital and physical-capital developments abroad, general country trends, and so on. The results suggest growth in ethnic scientific communities in the US increases foreign output with elasticities of 0.2-0.4, with the elasticity estimate depending upon how the data are weighted. The parameter estimates are statistically significant and robust across a wide class of specifications. The positive benefits are evident throughout the manufacturing industries studied, and the output expansion is decomposed into employment and labor productivity gains.

Estimated technology transfers between countries may be capturing the true diffusion process, or they could simply be correlated with omitted factors. Reverse causality is also a prominent concern, where human-capital developments in the foreign country could simultaneously result in higher output growth and more ethnic researchers emigrating to the US. Section 5 returns to the theoretical model to highlight how immigration quotas offer a foothold for addressing these issues. The resulting reduced-form strategy is applied in the context of the Immigration Act of 1990, a major revision of the US quotas system that led to a surge in the immigration of scientists and engineers from previously constrained countries. The immigration quotas exercise suggests that growth in US ethnic research communities increases foreign output with elasticities of 0.30.4. While the coefficients of the two approaches cannot be directly compared, the qualitative directions support each other.

Finally, the diverse set of countries studied affords additional insights regarding how the benefits accruing to technology followers differ by development stage. An extension to the theoretical model allows sector reallocation from agriculture to manufacturing. After a transition point to full employment in the manufacturing sector, greater technology transfer raises labor productivity and output levels with constant employment. This is the steady-state description developed in Section 2. Prior to this transition, however, the following country responds with growth in manufacturing employment as well as labor productivity gains. Consistent with these predictions, interactions with development stage show labor productivity growth is mostly concentrated in economies that have transitioned to full manufacturing employment (e.g., the Asian tiger economies); countries with large agricultural sectors instead increase industry output through higher employment levels (e.g., Mainland China, India).

The results of this project suggest poor access to the tacit knowledge regarding new innovations does contribute to slow technology diffusion. Ethnic channels are important for the transfer of this practical or informal information, and thus differences in ethnic research communities in frontier economies are partly responsible for the heterogeneous technology opportunities of developing countries. The paper concludes in Section 6 with a discussion of related projects currently being pursued with the ethnicity approach that will further refine our understanding of how these tacit knowledge channels operate. ${ }^{5}$

\footnotetext{
${ }^{5}$ In addition to characterizing technology diffusion, quantifying these ethnic linkages is important in its own right. Saxenian's work is frequently discussed in the "brain drain" versus "brain circulation" debate regarding high-skilled immigration to advanced countries. The structured econometrics of this study are an important
} 


\section{Theoretical Framework}

This section outlines a simple technology transfer model between a frontier country and a following nation. Both economies feature a manufacturing sector characterized by an expandingproduct-variety production function where technological progress occurs through the adoption of new intermediate products used in production of final goods. Entrepreneurial scientists living in each country supply these new technologies for profit, and they can either invent the intermediate products themselves or imitate foreign innovations.

The invention process is characterized by a "standing on the shoulders of giants" framework, where spillovers from past innovations increase the research productivity of current scientists and generate endogenous growth. ${ }^{6}$ Knowledge is local, however, in that a country's researcher productivity for invention builds only on its own past research. That is, the capabilities of the two nations to invent evolve separately.

Researchers can alternatively imitate foreign inventions for use in their own country. Their effectiveness in doing so, however, depends upon their tacit knowledge with respect to the foreign country's innovations. In preparation for the empirical analysis, ethnicity is incorporated into the framework to model this tacit knowledge channel. Specifically, the following country is of homogeneous ethnicity; the frontier country is primarily of another ethnicity but is home to some researchers of the following country's ethnicity. These frontier expatriates acquire and transmit the tacit knowledge necessary for effective imitation in the following country.

To greatly simplify the exposition, the frontier economy is labeled the US and the following economy is labeled China. Variables for the US economy are denoted by a tilda (e.g., $\tilde{Y}$ ), while China's variables are in plain font (e.g., $Y$ ). Superscripts and subscripts further distinguish ethnicity and sector as required. The first section outlines the core elements of China's economy, followed by differences in the US economy. The steady-state outcome is then characterized. The section closes with simulations of the transitional dynamics to this steady-state. ${ }^{7,8}$

\subsection{China's Economy}

China's economy contains $L$ workers of homogeneous ethnicity employed in manufacturing and research. Its labor market is competitive, such that workers are free to move between the two sectors and are paid their marginal product of labor in each. Denote the workers employed in manufacturing and research by $L_{M}$ and $L_{R}$, respectively. The behavior of the manufacturing sector is first described, followed by the research sector and a brief description of the consumer

complement to case studies for evaluating these arguments.

${ }^{6}$ For example, Romer (1990), Rivera-Batiz and Romer (1991), and Barro and Sala-i-Martin (1995).

${ }^{7}$ Technology flows are the only interactions between the two countries. The model abstracts from trade, and immigration is restricted in the base scenario.

8 "China" is selected for the following-country label due to the prominence of the Chinese ethnicity in the empirical findings. This labeling brings to the forefront the contrast of Mainland China and the Chinese tiger economies of Hong Kong, Singapore, and Taiwan discussed below. 
side of the economy.

The competitive manufacturing sector produces final goods $Y_{M}$ that can be consumed or used to make intermediate manufacturing goods. The price of final goods is normalized to one. Production for a representative firm $i$ that employs labor $L_{M_{i}}$ and non-durable intermediates $X_{i j}$ of type $j$ takes the form

$$
Y_{M_{i}}=A L_{M_{i}}^{1-\alpha} \sum_{j=1}^{N}\left(X_{i j}\right)^{\alpha} .
$$

$\alpha$ is the elasticity of output with respect to intermediate inputs $(0<\alpha<1), A$ is a common manufacturing productivity parameter, and $N$ is the number of intermediate product varieties currently available in China. In equilibrium firms employ equal amounts of all intermediate inputs $\left(X_{i j}=X_{i} \forall j\right)$ and (1) can be simplified to $Y_{M_{i}}=A L_{M_{i}}^{1-\alpha} X_{i}^{\alpha} N=A L_{M_{i}}^{1-\alpha}\left(N X_{i}\right)^{\alpha} N^{1-\alpha}$. Thus, the production function exhibits constant returns to scale in labor and total intermediate inputs $N X_{i}$, but a larger number $N$ of intermediate goods increases output by distributing the total intermediate inputs over more goods and thereby raising the marginal product of each.

Technical progress takes the form of increases in $N$, either through inventions $I$ or imitations $M$ of US inventions $(N=I+M)$. Entrepreneurial research firms choose between invention and imitation by comparing the productivity of the two techniques. The research productivity for invention in China is determined by the existing stock of China's inventions, or $\partial I / \partial t=I \cdot L_{R}$. There are no international knowledge spillovers in the sense that researchers in China cannot build on the US stock of inventions directly in innovation. China's researchers can alternatively imitate US inventions at a rate

$$
\frac{\partial M}{\partial t}=\left(\tilde{I} \Psi\left[\frac{M}{\tilde{I}}\right]\left(\tilde{H}^{C}\right)^{\beta}\right) \cdot L_{R},
$$

where $\tilde{I}$ is the US invention stock and $\tilde{H}^{C}$ is the Chinese human-capital stock with respect to US inventions. A larger stock of US inventions affords a larger pool of technologies that can be imitated, thus raising the imitation productivity for a researcher in China. The imitation of products exhausts the available pool, however, and the function $\Psi$ decreases with the ratio of imitated products to the available US stock, $\Psi^{\prime}<0 . \quad \Psi[1]=0$ when all available products have been imitated, and $\Psi[0]$ is sufficiently large to ensure some imitation occurs with human capital for foreign technologies. The $\left(\tilde{H}^{C}\right)^{\beta}$ specification models that tacit knowledge of US inventions is necessary for successfully adopting them in China. This human-capital stock depreciates at a rate $\delta$, and the population of Chinese researchers in the US undertaking inventive activity adds to it: $\partial \tilde{H}^{C} / \partial t=-\delta \tilde{H}^{C}+\tilde{L}_{R}^{C}$. If the number of US Chinese researchers is constant, the steady-state stock of Chinese human capital with respect to US inventions is $\delta^{-1} \tilde{L}_{R}^{C}$.

Regardless of how new products are acquired, the entrepreneurial research firms gain perpetual monopoly rights over the production and sale of new intermediate goods in China. The 
present discounted value of these rents for a good $j$ at time $t$ is

$$
V(t)=\int_{t}^{\infty}\left(P_{j}-C_{j}\right) X_{j} e^{-\bar{r}(s, t) \cdot(s-t)} d s
$$

where $P_{j}$ is the selling price and $C_{j}$ is the cost of producing the intermediate good. $\bar{r}(s, t)$ is the average interest rate between times $t$ and $s$, which is constant in equilibrium. $C_{j}=1$ for all research firms as one unit of $Y_{M}$ is required to produce one unit of an intermediate input.

Monopoly rights afford research firms the power to set $P_{j}$ in each period to maximize $\left(P_{j}-\right.$ 1) $X_{j}$. As price takers, the manufacturing firms equate the marginal product of an intermediate good, $\partial Y_{M_{i}} / \partial X_{i j}$ in (1), with its price $P_{j}$ for a demand of $X_{i j}=\left(A \alpha / P_{j}\right)^{1 /(1-\alpha)} L_{M_{i}}$. Substituting this demand function into the research firm's maximization problem, summing across final-goods producers, and taking the derivative with respect to $P_{j}$ yields the monopoly price $P_{j}=\alpha^{-1}$. Thus, research firms charge the same price $\left(P_{j}=P\right)$ and face similar aggregate demands of $X=A^{1 /(1-\alpha)} \alpha^{2 /(1-\alpha)} L_{M}$. The constant interest rate, price, and aggregate demand relationships simplify the value of inventing or imitating a new technology (3) to

$$
V=\left(\frac{1-\alpha}{\alpha}\right) A^{1 /(1-\alpha)} \alpha^{2 /(1-\alpha)} \frac{1}{r} L_{M} .
$$

Constant intermediate demand functions also simplify China's aggregate output,

$$
Y_{M}=A^{1 /(1-\alpha)} \alpha^{2 \alpha /(1-\alpha)} L_{M} N
$$

On the consumer side, households maximize a linear lifetime utility function $U=\int_{0}^{\infty} c(t)$. $e^{-\rho t} d t$, where $\rho$ is the rate of time preference. Consumers earn wage $w$ and receive the interest rate $r$ on savings. In equilibrium, $\rho=r$.

\subsection{US Economy}

Before the equilibrium for China's economy can be determined, the US economy must be described. The US economy is identical to China's except in its ethnically heterogeneous labor force and in its invention of new intermediate goods. Workers of both English and Chinese ethnicity live in the US. English workers move between the manufacturing and research sectors, but Chinese expatriates work only in the research sector $\left(\tilde{L}_{M}=\tilde{L}_{M}^{E}, \tilde{L}_{R}=\tilde{L}_{R}^{E}+\tilde{L}_{R}^{C}\right)$. The Chinese population in the US is small enough to ensure some English scientists are always required. The aggregate populations of China and the US are equal $(L=\tilde{L})$.

Researchers of both ethnicities contribute to and utilize the existing US invention stock $\tilde{I}$ in developing new intermediate products: $\partial \tilde{I}^{C} / \partial t=\tilde{I} \cdot \tilde{L}_{R}^{C}$ and $\partial \tilde{I}^{E} / \partial t=\tilde{I} \cdot \tilde{L}_{R}^{E}$, where $\tilde{I}=\tilde{I}^{C}+\tilde{I}^{E}$. This research specification again highlights the role of past inventions $\tilde{I}$ in making current researchers more productive, and assumes inventions made in China do not contribute to US researcher productivity for invention. More subtly, ethnicity does not matter for invention 
in the US - Chinese and English scientists are symmetric with respect to the US invention stock. Finally, US researchers of Chinese ethnicity can imitate products made in China with a productivity analogous to $(2) .^{9}$

\subsection{Steady-State Description: US Invents, China Imitates}

This case determines the core estimating equation for this study. Without invention in China, the US economy operates in isolation, and imitation does not occur $(\tilde{N}=\tilde{I})$. The US research sector is competitive with respect to labor markets, and scientists earn the marginal product of their innovative efforts. Denote by $\tilde{V}$ the present discounted value of making a new invention in the US. As researchers invent $\tilde{I}$ new products each period (i.e., $(\partial \tilde{I} / \partial t) / \tilde{L}_{R}=\tilde{I}$ ), the wage paid to scientists is $\tilde{V} \cdot \tilde{I}$. Likewise, wages in the manufacturing sector are equal to the marginal product of labor $(1-\alpha) \tilde{Y}_{M} / \tilde{L}_{M}$. Labor mobility between sectors requires that these wages be equal, $\tilde{V} \cdot \tilde{I}=(1-\alpha) \tilde{Y}_{M} / \tilde{L}_{M}$. Substituting into this free-entry condition the US versions of the value of innovations (4) and aggregate output (5), and noting $r=\rho$, the steady-state allocation of labor in the US economy is found to be $\tilde{L}_{M}=\rho / \alpha$ and $\tilde{L}_{R}=L-\rho / \alpha$. Thus, the growth rate of both the stock of US intermediate technologies and manufacturing output is $L-\rho / \alpha$.

Returning to China's economy, all intermediate products come through imitation of US goods $(N=M)$. Labor mobility again requires that wages be equal across China's research and manufacturing sectors,

$$
V \cdot\left(\tilde{I} \Psi\left[\frac{M}{\tilde{I}}\right]\left(\tilde{H}^{C}\right)^{\beta}\right)=(1-\alpha) \frac{Y_{M}}{L_{M}} .
$$

Substituting in the value of new intermediates $V$ from (4) and aggregate output $Y_{M}$ from (5),

$$
r=\frac{\tilde{I}}{M} \Psi\left[\frac{M}{\tilde{I}}\right]\left(\tilde{H}^{C}\right)^{\beta} \alpha L_{M} .
$$

With identical preferences and aggregate populations, China's interest rate and allocations of labor to manufacturing and research are the same as the US. ${ }^{10}$ Equation (6) further shows the steady-state ratio of China's imitated products to available US products $M / \tilde{I}$ is constant and increases with the Chinese human-capital stock with respect to US technologies $\left(\Psi^{\prime}<0\right)$. Stronger tacit knowledge improves researcher productivity for imitation in China and closes the steady-state gap to the US frontier.

Simplifying (6) for economies of equal size relates China's imitated technology stock to the US technology frontier and China's tacit knowledge for US innovations,

$$
M=\tilde{I} \Psi\left[\frac{M}{\tilde{I}}\right]\left(\tilde{H}^{C}\right)^{\beta} .
$$

\footnotetext{
${ }^{9}$ The potential crowding out of US workers and students from science and engineering fields by immigrants is often debated (e.g., Borjas 2004, Freeman 2005). This model incorporates a crowding-out effect for analytical convenience only.

${ }^{10}$ These conditions hold for more general utility functions. As Barro and Sala-i-Martin (1995) note, technological diffusion can equalize rates of return without other interactions between economies.
} 
Substituting this relationship into China's manufacturing output (5),

$$
Y_{M}=A^{1 /(1-\alpha)} \alpha^{2 \alpha /(1-\alpha)} L_{M} \cdot\left(\tilde{I} \Psi\left[\frac{M}{\tilde{I}}\right]\left(\tilde{H}^{C}\right)^{\beta}\right) .
$$

Taking logs and collapsing time-invariant terms into a constant $\phi$, China's manufacturing output depends upon its human-capital stock with respect to US research with elasticity $\beta, \ln \left(Y_{M}\right)=$ $\phi+\ln (\tilde{I})+\beta \ln \left(\tilde{H}^{C}\right)$. The human-capital stock is $\delta^{-1} \tilde{L}_{R}^{C}$ in steady-state, so that

$$
\ln \left(Y_{M}\right)=\phi+\ln (\tilde{I})+\beta \ln \left(\tilde{L}_{R}^{C}\right)
$$

where $\delta^{-1}$ is absorbed into the constant. Equation (8) is the basis for the estimating equations employed in Sections 4 and 5. The statistical framework will return to the intricacies of empirically estimating this relationship, but the outlook is promising that the relationship will be directly identified if this scenario holds.

The imitation-versus-invention decision in China determines the condition required for this steady-state description. Specifically, the productivity of researchers for undertaking invention in China must be less than the researcher productivity for imitating US innovations in equilibrium,

$$
I<\tilde{I} \Psi\left[\frac{M}{\tilde{I}}\right]\left(\tilde{H}^{C}\right)^{\beta} .
$$

The assumption $I=0$ requires (9) hold forever; without a knowledge stock on which to build, a first invention is impossible. While this is a valid description for extremely poor regions, the more interesting implication for developing or emerging countries is that even with a small invention stock, the comparative benefit to imitation can be sustained so long as tacit knowledge for a growing stock of frontier innovations is maintained. Section 5 discusses the case where (9) no longer holds. ${ }^{11}$

\subsection{Agriculture to Manufacturing Sector Reallocation}

The steady-state characterization of China's economy builds on the assumption of full employment in the manufacturing and research sectors. While the estimating equation (8) relates China's output to its research presence in the US, the same elasticity $\beta$ would hold for labor productivity specifications. With full employment, output gains can only come through labor productivity enhancements. Many developing economies have large agricultural sectors, however, and the migration from agriculture to manufacturing is important for characterizing economic development (e.g., Harris and Todaro 1970).

This section incorporates into the basic model an agricultural sector in China. The framework highlights how technology transfer induces a different response when sector reallocation is

\footnotetext{
${ }^{11}$ Immigration is restricted in this framework. Moreover, Chinese workers would prefer to emigrate to the US as the US wage rate is higher ceteris paribus due to the larger stock of intermediate goods.
} 
possible. Specifically, as more technologies are transferred from the US to China, labor shifts from agriculture to the manufacturing and research sectors. After a sufficient number of frontier innovations have been imitated, China's economy transitions to full employment in the manufacturing and research sectors. Thus, the steady-state of the expanded economy is the same as the basic framework described above; numerical simulations of the transition path, however, offer additional guidance for the empirical exercises this study undertakes.

The agricultural sector for China is characterized by a decreasing returns to scale technology that employs only labor $L_{A}$,

$$
Y_{A}=B L_{A}-\frac{1}{2} L_{A}^{2}
$$

$B$ is a common agricultural productivity parameter, and the final goods from agriculture and manufacturing are identical $\left(Y=Y_{A}+Y_{M}\right)$. Labor is again free to move across sectors, and the proportion of the labor force allocated to each of the three sectors along the development path can be related to China's technology stock. China is assumed to possess only imitated technologies $(M=N)$.

First, the marginal products of labor for agriculture and manufacturing are $B-L_{A}$ and $(1-\alpha) A^{1 /(1-\alpha)} \alpha^{2 \alpha /(1-\alpha)} M$, respectively. Wage equality between these two sectors relates the size of the agricultural workforce to the number of imitated technologies,

$$
L_{A}=\max \left[B-(1-\alpha) A^{1 /(1-\alpha)} \alpha^{2 \alpha /(1-\alpha)} M, 0\right]
$$

Thus, growth in China's technology stock lowers agricultural employment until the economy reaches a transition point with full employment in the research and manufacturing sectors. This transition occurs when $M>(1-\alpha)^{-1} A^{-1 /(1-\alpha)} \alpha^{-2 \alpha /(1-\alpha)} B$. If this condition is satisfied in the current period, it will hold in all future periods as the wages of the manufacturing and research sectors continue to grow with further technological advancement. ${ }^{12}$ Likewise, the size of the manufacturing labor force can be related to China's existing technology stock and the US technology stock through the wage equality of the manufacturing and research sectors (6) and the interest rate $r=\rho$,

$$
L_{M}=\frac{M}{\tilde{I}} \Psi^{-1}\left[\frac{M}{\tilde{I}}\right]\left(\tilde{H}^{C}\right)^{-\beta} \frac{\rho}{\alpha} .
$$

With $L_{A}$ and $L_{M}$ determined, the number of researchers follows from the labor endowment. ${ }^{13}$

To characterize the transition path, a numerical solution for the steady-state without an agricultural sector is first developed. The labor forces of the two economies are taken to be of size 0.20. For parameter values of $\alpha=1 / 3$ and $\rho=0.05$, the allocation of labor to manufacturing

\footnotetext{
${ }^{12}$ The agricultural production function (10) bounds the marginal productivity of labor from above at $B$. This function does not satisfy the Inada conditions. An agricultural sector with a constant returns to scale production function employing land and labor yields an ever shrinking agricultural sector.

${ }^{13}$ Even if the Chinese human-capital stock for US technologies is stable during the transition period, the relative proportion of labor devoted to manufacturing versus research is not at its steady-state level due to adjusting fraction of imitated technologies $M / \tilde{I}$.
} 
and research is $0.15(75 \%)$ and $0.05(25 \%)$, respectively. As the growth rate of inventions in the US is equal to the size of its research labor force (i.e., $(\partial \tilde{I} / \partial t) / \tilde{I}=\tilde{L}_{R}$ ), the set of available frontier technologies grows at a rate of 5\%; the same growth rate is in turn found for China's imitated technology stock and the manufacturing outputs of the two countries. Specifying $A=1$, the steady-state value of new inventions or imitations in both economies is given a numerical value of $V=0.22$.

Examining more closely the technology transfer mechanism, the size of the Chinese research population living in the US is modeled as 0.001 (or $2 \%$ of the US researcher total). Taking an estimate of $\beta=0.3$ from the empirical exercises in Section 4 and assuming a depreciation on human capital of $\delta=0.15$, the steady-state human-capital stock is given a numerical value of $\tilde{H}^{C}=0.0067$. Finally, a functional form for $\Psi[M / \tilde{I}]$ must be specified to estimate the share of US technologies imitated by China. The form $\Psi[M / \tilde{I}]=0.5 \cdot(1-M / \tilde{I})$ retains the properties of $\Psi^{\prime}<0$ and $\Psi[1]=0$ and yields a steady-state imitation share $M / \tilde{I}=0.10$.

Turning to the transition path simulations to this steady-state, the solid line in Figure 1 describes the evolution of China's economy from the initial conditions of $90 \%$ employment in agriculture for China and $1 \%$ of US technologies imitated. ${ }^{14}$ The size of the agricultural sector corresponds to an initial stock of imitated technologies $M(0)$ in China, while the gap to the US frontier determines the technologies $\tilde{I}(0)$ in the US; the parameter $B=0.2$ is also specified. The US, assumed to be in steady-state growth, evolves exogenously with a $5 \%$ growth rate in its technology stock. From (11), (12), and the labor endowment, the evolution of China's economy is subsequently characterized.

The leftmost panel describes the allocation of labor along the transition path. For the baseline simulation, the Chinese human-capital stock with respect to US technologies remains at its steady-state level of 0.0067. Initially, limited labor is devoted to manufacturing or research. In this general equilibrium, the small market size of final-goods producers depresses the value of new innovations and the researchers employed, even though the large gap to the US frontier makes it very productive to imitate new intermediate products. Likewise, the labor demand of final-goods producers is limited due to the small technology stock in China.

As the number of technologies steadily expands, however, the agricultural sector shrinks and more labor is allocated to both manufacturing and research. This industrialization sustains itself as the growth in market size increases the value of new innovations, while the larger technology base increases the labor demand of final-goods manufacturers. The sector reallocation quickens as the economy approaches the transition point $(t=16)$. Around this transition, the researcher share of China's labor force reaches its peak, before gradually declining to its steady-state value of $25 \%$. The manufacturing labor share also surges around the transition, and continues to grow to its steady-state share of $75 \%$.

\footnotetext{
${ }^{14}$ Full employment in agriculture is an unstable equilibrium if Chinese human capital to US technologies exists. Once some labor is devoted to manufacturing and research, China's economy will eventually transition completely out of agriculture if tacit knowledge with respect to the US frontier is maintained.
} 
The middle panel presents several growth rates evident in China during the transition. Initial growth is slow due to the inertia of the large agricultural sector. Around the transition point, however, growth in China's imitated technology stock surges due to the extensive labor resources devoted to research and the still sizeable gap to the US frontier. This high rate of technology adoption translates into higher growth in both manufacturing output and labor productivity. The manufacturing output growth is not due solely to labor productivity gains, however, as the growth in employment contributes approximately the same amount. After the transition, the growth rates decline to their steady-state rates of $5 \%$.

Finally, the rightmost panel exhibits several levels with respect to the US frontier. As evident in research labor share, the linear preferences of consumers affords a substantial investment in the imitation of new technologies around the transition in return for higher future consumption. During this convergence period, China's technology gap to the US frontier is substantially narrowed. In the steady-state, the fraction of US technologies imitated by China translates directly into the steady-state fraction of US manufacturing output achieved, and the transition path dynamics take the same shape. Note, however, that China's total output level (including agriculture) relative to the US declines slightly during the transition period due to the investment in imitation. Except in the immediate vicinity of the transition point, China's output does not fall but instead fails to maintain pace with the US economy in steady-state growth. After this investment period, however, the share rises sharply to a long-run level equal to the manufacturing output share.

From this baseline, the dotted line in Figure 1 plots a second transition path for an exogenous increase in the number of Chinese researchers living in the US from 0.001 to 0.004 on date $t=3 .^{15}$ While these simulations are meant to be illustrative, the fourfold rise from $2 \%$ to $8 \%$ of the US research community is roughly in line with the growing Chinese research contribution in several high-tech industries for the period studied in the empirical analysis below. As the top left panel shows, this exogenous increase does not immediately translate into a fourfold increase in the Chinese human-capital stock with respect to US technologies. The human-capital stock instead grows over time with the higher rate of tacit knowledge gain in each period following the US Chinese researcher growth.

As the boost in technology transfer is realized, however, the transition from agriculture proceeds at a more rapid pace. The growth rate of manufacturing output spikes upward due to both higher growth in imitated technologies and more labor reallocation. An economy without an agricultural sector would only experience output growth due to labor productivity gains. In the new steady-state, the fourfold increase in China's human-capital stock results in an approximate $40 \%$ levels gain in imitated technologies and output; the percentage of US technologies imitated is also higher. China's growth rate and allocation of labor, though, are the same as in the simulation without the exogenous increase in scientific integration.

\footnotetext{
${ }^{15}$ The simulations abstract from any growth in the overall size of the US labor force due to this inflow.
} 
In summary, technology transfer to economies with large agricultural sectors can increase manufacturing output through both labor productivity gains, as in the steady-state scenario, and through employment growth. In this particular framework, the productivity gains and employment gains are of roughly similar magnitude. In alternative models, however, output growth would come only through labor reallocation. ${ }^{16}$ After evaluating the core steady-state specification (8), Section 4 empirically evaluates how the responses of economies with large agricultural sectors differ from those with constrained labor resources.

\section{Ethnic Patenting and International Citations Analysis}

Estimation of the $\beta$ parameter requires quantifying each ethnicity's human-capital stock with respect to US research. This section outlines the dataset built for this exercise, and presents an initial analysis of knowledge flows using international patent citation records. The ethnic patenting data are then joined with foreign output metrics in the next section to evaluate (8) directly.

\subsection{Ethnic Patenting Records}

Ethnic technology development in the US is quantified through the NBER Patent Data File (Hall, Jaffe, and Trajtenberg 2001). This dataset offers detailed records for all patents granted by the United States Patent and Trademark Office (USPTO) from January 1975 to December 1999. Each patent record provides information about the invention (e.g., technology classification, citations of prior art) and the inventors submitting the application (e.g., name, city). To estimate ethnicities, a commercial database of ethnic first names and surnames is mapped into the inventor records. The match rate is $99 \%$ for US patent records, and the process affords the distinction of nine ethnicities: Chinese, English, European, Hispanic, Indian, Japanese, Korean, Russian, and Vietnamese.

Table 1 describes the 1985-1997 US sample. The trends demonstrate a growing ethnic contribution to US technological development, especially among Chinese and Indian scientists. Also matching popular perceptions, ethnic inventors are more concentrated in high-tech industries like computers and pharmaceuticals and in gateway cities relatively closer to their home countries (e.g., Chinese in San Francisco, European in New York, and Hispanic in Miami). The final three rows demonstrate a close correspondence of the estimated ethnic composition to the countryof-birth composition of the US science and engineering workforce in the 1990 Census. ${ }^{17}$ Figure 2 illustrates the evolving ethnic contribution to US technology development as a percentage of

\footnotetext{
${ }^{16}$ For example, specifications with constant outside wages and a fixed stock of physical capital. As the technology transfer increases the marginal product of labor, producers hire more labor to bring the marginal product of labor back down to the external wage. The agricultural sector's production function (10) instead allows the marginal product of labor in agriculture to increase in step with the manufacturing sector's wage.

${ }^{17}$ The estimated European ethnic contribution is naturally higher than the immigrant contribution measured by foreign born.
} 
patents granted by the USPTO, while Figure 3 provides a more detailed glimpse of ethnic shares by broad technology groups. While the name-matching procedure certainly misclassifies the ethnicities of some inventors, the aggregate trends important for this study appear remarkably accurate.

The ethnic-name database is also applied to foreign patent records registered in the US. Inventions originating outside the US account for just under half of USPTO patents, with applications from Japan comprising $45 \%$ of this foreign total. The rows of Table 2 present the matched characteristics for countries and regions grouped to the ethnicities identifiable with the database. From a quality-assurance perspective, the results are very encouraging. First, the ethnic-name database assigns ethnicities to a large percentage of foreign records (overall matching rate of 98\%). Second, the estimated inventor compositions are quite reasonable, with the own-ethnicity contributions in all but three regions being greater than $80 \%$. Similar to the US, own-ethnicity contributions should be less than $100 \%$ due to foreign researchers. ${ }^{18,19}$

\subsection{International Patent Citation Analysis}

In addition to serving as a quality-assurance check, patents registered with the USPTO by foreign inventors afford an initial characterization of international knowledge flows through ethnic scientific networks. Each patent record includes citations of prior inventions on which the current patent builds, and the pattern of these citations can be informative about communication channels between researchers. This first exercise simply compares the ethnic composition of cited US inventors across different foreign inventor ethnicities. That is, do Chinese inventors living outside of the US tend to cite more Chinese inventors living in the US than their technology field would suggest?

Inventor names are only included with patents granted from 1975-1999, and the data are cut in two ways to form a uniform sample. First, only the citations of foreign patent applications to the USPTO from 1985-1997 are considered. Second, the application year of the cited US patent must be within ten years of the application date of the citing foreign patent. That is, citations of 1975-1984 US domestic patents are considered for foreign patents applied for in 1985, while 1976-1985 is the appropriate ten-year window for 1986 patents. In addition, all within-company citations and patents with inventors in multiple countries are excluded. ${ }^{20}$

\footnotetext{
${ }^{18}$ Kerr (2005) documents the matching algorithms and provides additional descriptive statistics.

${ }^{19} \mathrm{~A}$ further supplement to the NBER patent data is important to highlight. The USPTO issues patents by technology categories rather than by industries. Combining the work of Johnson (1999) and Silverman (1999), concordances are developed between the USPTO classification scheme and the three-digit industries in which new inventions are manufactured or used. The main estimations focus on industry-of-use, affording a composite view of the technological opportunity developed for an industry. Studies of advanced economies find accounting for these inter-industry R\&D flows important (e.g., Scherer 1984). Keller (2002a) reports inter-industry R\&D flows aid productivity growth significantly within OECD countries, equal to half or more of the own-industry development. Estimations with manufacturing industries support the using-industry specifications.

${ }^{20}$ Patents may have multiple inventors with different ethnicities. The reported regressions only consider citations for which a dominate ethnicity can be assigned to both patents (i.e., a single ethnicity accounts for strictly more than $50 \%$ of multiple inventors). English-ethnicity inventors abroad are excluded.
} 
From this sample, citation counts are developed by cells that contain four dimensions: 1) the ethnicity of the citing foreign inventor, 2) the ethnicity of the cited US inventor, 3) the technology class of the citing foreign inventor, and 4) the technology class of the cited US inventor. The latter two dimensions are necessary for isolating ethnicity's role since patents cite other patents within their technology field far more frequently than those outside of their field. If ethnicities concentrate in different industries in the US and abroad, measured ethnic flows could be merely capturing that technologies build upon prior art in their own discipline.

More than 100,000 cells are formed with this organization, and many cells contain zero values. The zero values are due to both the small sizes of some ethnicities (e.g., Vietnamese inventors outside of the US) and that researchers in a given field simply do not cite the universe of technologies in their work. Count data containing zero values can be appropriately handled with a Negative Binomial model. ${ }^{21}$ The counts are regressed on an indicator variable for whether the citing foreign ethnicity and cited US ethnicity are the same, as well as vectors of fixed effects for each of the four dimensions on which cells are formed. These fixed effects remove basic levels differences between the series (e.g., the English ethnicity in the US receiving uniformly more citations, Vietnamese researchers abroad making uniformly fewer inventions and citations). An indicator variable is also included for whether the cited and citing technology category are the same.

The coefficient on the indicator variable for same-ethnicity is transformed into an incidence rate ratio that gives the higher rate of citations within an ethnic group. The first column of Table 3 reports the incidence rate ratio for all citations, finding a moderate effect that ownethnicity citations are 50\% higher than citations to other ethnicities, once the basic levels and industry effects are removed. This coefficient is statistically different from one, the level where own-ethnicity citations have the same frequency as citations of other ethnicities. To further study the time path of these knowledge flows, the Negative Binomial regressions are performed separately for each citation lag of one to ten years, rather than collapsing the data into a single regression. The coefficients from these regressions are also reported in Table 3 . Common ethnicity appears most important for international technology diffusion in the first few years after a patent is made, peaking in a citation lag of four to five years. ${ }^{22}$

\footnotetext{
${ }^{21}$ Wooldridge (Ch. 19, 2002) describes the statistical properties of the Negative Binomial regression.

${ }^{22}$ Thompson and Fox-Kean (2004) criticize the USPTO categories as being too broad to control effectively for technology specialization. Thompson (2005) proposes an alternative approach that compares inventoradded citations to those added by the USPTO examiner, a distinction only made after 2000. Estimations using Thompson's technique and dataset yield a quantitatively similar role for own-ethnicity in international citations.

Jaffe, Trajtenberg, and Fogarty (2002) provide additional documentation on inferring communication channels from patent citations, while Jaffe, Trajtenberg, and Henderson (1993), Peri (2004), Hu and Jaffe (2004), and Agrawal, Cockburne, and McHale (2004) are examples of applications in an international distance context.
} 


\section{Output and Productivity Analysis}

The international patent citation exercises confirm knowledge diffusion occurs at an uneven rate across countries and further verify that knowledge networks are important for short-run technology transfer from the US. The focus of this study, however, is whether greater tacit knowledge with respect to all US innovations translates into economic improvements for foreign countries. To evaluate this proposition, the US ethnic patenting trends are joined with additional data on foreign manufacturing industries. The combined dataset is first described, and an empirical extension of specification (8) that accounts for the features of the combined dataset is developed and estimated.

\subsection{Foreign Manufacturing Data}

The benefit of knowledge integration for foreign development is evaluated through the Industrial Statistics Database of the United Nations Industrial Development Organization (UNIDO). The UNIDO collects industry-level manufacturing statistics for The International Yearbook of Industrial Statistics and specialized publications on topics like development and competition. Researchers at the UNIDO supplement the data resources of the OECD with national records for non-OECD members, creating a unique global resource. The UNIDO's stated objective is the compilation of internationally comparable and internally consistent series (e.g., variable definitions, accounting units, collection procedures).

Table 4 describes the sample and lists the three-digit ISIC industries. ${ }^{23}$ The panels include all country-industry observations surveyed at least four times from 1985-1997 that correspond to non-English ethnicities identifiable with the ethnic-name database (e.g., Canada, the United Kingdom, Africa, and the Middle East are excluded). Three industry characteristics are considered: output, employment, and labor productivity measured as output per employee. Table 4 aggregates the annual industry-level data to describe the country-level manufacturing sectors. While direct comparisons across countries are limited with an unbalanced panel, the output and labor productivity differences between industrialized countries (e.g., Japan) and developing nations are clearly evident. The underlying industry-level metrics also agree with published UNIDO and World Bank statistics.

The UNIDO dataset is inappropriate for studies of industry creation or destruction due to its unbalanced panel and industry aggregation. Recognizing this limitation and in order to enhance the quality of estimations, country-industry observations must maintain ten employees and one US ethnic patent per annum. These minimums exclude poor quality data, but raising or removing these hurdles does not significantly affect the findings. ${ }^{24}$

\footnotetext{
${ }^{23}$ The UNIDO collects data at the three-digit and four-digit industry levels of the International Standard Industrial Classification (ISIC). This presentation focuses on the three-digit aggregation, but the four-digit data delivers similar results. While sacrificing industries (28 versus 80 ), the three-digit dataset contains more countries (43 versus 20), better coverage of Chinese economies, and more capital data.

${ }^{24}$ Specifications employing alternative UNIDO data on industry value-added and establishments mirror the
} 


\subsection{Output and Productivity Estimation Framework}

The combined dataset affords an industry-level analysis of technology transfer with multiple countries and ethnicities. Extending (8) to industry $i$ and country $c$ of ethnicity $e$,

$$
\ln \left(Y_{c i}\right)=\phi_{c i}+\ln \left(\tilde{I}_{i}\right)+\beta \ln \left(\tilde{L}_{R, e i}\right) .
$$

While analytically convenient, this steady-state description must be adapted for the empirical exercises. In particular, the ethnic human-capital stocks for US technologies change over the 1985-1997 period (and are indeed the source of identification for the $\beta$ parameter). The citation regressions in Table 3 highlight that ethnic ties have an important lag structure, especially for the first five years of knowledge dissemination. Rewriting (13) in discrete time to model this five-year dependency,

$$
\ln \left(Y_{c i t}\right)=\phi_{c i}+\ln \left(\tilde{I}_{i t}\right)+\beta \ln \left(\sum_{s=1}^{5} \tilde{L}_{R, e i, t-s}\right) .
$$

Unfortunately, existing data on the ethnicity of the US scientific workforce are limited. While Census estimates provide strong cross-sectional descriptions (i.e., country-of-birth, industry), they lack the necessary longitudinal detail. Other resources like the Current Population Survey and National Science Foundation reports offer only coarse cross-sectional distinctions. Ethnic patenting data, however, are a solid foothold for estimating the scientific research of ethnicities in the US. Rewriting the US researcher productivity function into a discrete-time form for industry $i$ and ethnicity $e, \tilde{I}_{\text {eit }}^{\text {Flow }}=\tilde{I}_{i t} \cdot \tilde{L}_{R, e i t}$. The measured patenting of ethnicity $e$ in year $t$ again depends upon the overall stock of US knowledge and the size of the ethnic research group in the US (measured at the beginning of the year). By abstracting from the endogenous growth stimulus, the researcher productivity becomes time-invariant: $\tilde{I}_{i t}=\tilde{I}_{i t_{0}}$. Thus, the US ethnic research community can be inferred from the patent flow divided by the constant researcher productivity $\left(\tilde{L}_{R, e i t}=\tilde{I}_{i t_{0}}^{-1} \cdot \tilde{I}_{\text {eit }}^{\text {Flow }}\right)$. Substituting this simplified form into (14),

$$
\ln \left(Y_{c i t}\right)=\phi_{c i}+\ln \left(\tilde{I}_{i t}\right)+\beta \ln \left(\tilde{I}_{i t_{0}}^{-1} \sum_{s=1}^{5} \tilde{I}_{e i, t-s}^{\text {Flow }}\right) .
$$

The time-invariant researcher productivity $\tilde{I}_{i t_{0}}^{-1}$ is separated from the patent sum and incorporated with $\ln \left(\tilde{I}_{i t}\right)$ into an industry-year fixed effect $\eta_{i t}$. Likewise, the base productivity constants $\phi_{c i}$ are extended into country-industry fixed effects.

To keep the exposition simple, define $P A T_{\text {eit }}^{U S}$ to be the five-year sum of recent US ethnic patenting in an industry. The core estimating equation becomes

$$
\ln \left(Y_{c i t}\right)=\alpha+\beta \ln \left(P A T_{\text {eit }}^{U S}\right)+\phi_{c i}+\eta_{i t}+\epsilon_{c i t}
$$

output and employment results presented below. The 1985-1997 period balances data inclusion with maintaining a consistent sample, as data for earlier or later years are quite limited. Similar outcomes are evident if all 19802000 data are employed or if the sample is restricted to a 1985-1997 balanced panel of continually surveyed countries and industries. 
where $\phi_{c i}$ and $\eta_{i t}$ are the vectors of country-industry and industry-year fixed effects, respectively. These fixed effects warrant careful discussion. First, the country-industry effects $\phi_{c i}$ remove levels differences between series. Without $\phi_{c i}$, a positive $\beta$ would be found if output in China's computer industry and US Chinese research in the computer industry are higher than average. Incorporating $\phi_{c i}$ instead requires the output growth in China's computer industry be above average if the US Chinese computer research growth is above average. Focusing on relative growth rates removes time-invariant factors that potentially confound the analysis (e.g., the productivity parameters $A$, ethnicity size).

The derivation of (15) highlights two important roles for the industry-year fixed effects $\eta_{i t}$. First, $\eta_{i t}$ extract the overall growth in the US knowledge stock for an industry (e.g., the strong increase in computer and pharmaceutical research vis-à-vis mechanical research). Second, $\eta_{i t}$ control for the invention productivity of researchers, so that ethnic patenting flows are viable proxies for ethnic research in the US. More generally, the industry-year effects remove all industry trends common to the countries in the sample (e.g., higher worldwide demand for computers and pharmaceuticals) and fluctuations in patent statistics due to changes in USPTO resources (e.g., Griliches 1990). ${ }^{25}$

These fixed effects are crucial for the interpretation of the $\beta$ parameter. This project does not estimate the effect of US patenting on foreign output and productivity; indeed, isolating that specific channel from other knowledge flows between countries is not feasible with industry-level outcomes. Moreover, the substantial increase in the number of patents granted by the USPTO over the last two decades is difficult to interpret. ${ }^{26}$ Instead, (15) forces variation to be within industries, isolating the size of ethnic communities from aggregate industry trends. A positive $\beta$ coefficient requires that higher relative growth of Chinese computer research compared to Indian computer research in the US correlate with higher relative output growth in China's computer industry compared to India's computer industry.

Finally, the five-year patent sums $P A T_{\text {eit }}^{U S}$ are developed for each ethnicity-industry from the patent database. Multiple nations map into the nine ethnicities available with the ethnic-name database, and the same industry-level patenting series from the US is applied to each country within an ethnicity (i.e., Mexican or Chilean scientists cannot be separated from the Hispanic total). The empirical analysis accounts for this multiplicity by conservatively clustering standard errors at the ethnicity-industry level; this cross-sectional clustering further addresses the serialcorrelation concerns of Bertrand, Duflo, and Mullainathan (2004). Robustness checks also

\footnotetext{
${ }^{25}$ Industry-year effects extract industry-specific price movements (e.g., the rapid decline of computer prices). The UNIDO converts output data from foreign currencies to nominal US dollars using average yearly exchange rates (IMF International Financial Statistics Series rf).

${ }^{26}$ For example, Kortum and Lerner (2000), Kim and Marshcke (2004), Hall (2004), and Branstetter and Ogura (2005).
} 
examine whether the large European and Hispanic blocs significantly influence the results. ${ }^{27,28}$

\subsection{Basic Output and Productivity Regressions}

Table 5A reports the primary results for (15). The first row demonstrates that output consistently rises with strong scientific integration to the US. As both variables in logs, the 0.241 coefficient in the upper-left corner finds a $0.24 \%$ increase in foreign output with a $1 \%$ increase in US ethnic research. As discussed earlier, industry output expansion can come through both labor productivity gains and expansion in employment. Disaggregating the output regression, Panels B and C find labor productivity growth facilitates most of the manufacturing development captured in this sample.

Three weighting schemes are tested: no weights, weighted by the 1985-1987 industry-level patenting in the US, and weighted by the 1985-1987 size of the foreign manufacturing industry. The $\beta$ coefficients in the patent-weighted regressions are consistently larger than the unweighted regressions as this scheme emphasizes high-tech industries and the strong interactions of the Chinese and Indian research communities with their home countries. The output weights instead focus on the largest industries and offer a sense of the average treatment effect for industries. Coefficient estimates tend to marginally lower for the output weights than the patent weights due to their greater emphasis on traditional economic sectors (e.g., food products, textiles). Both approaches, however, yield more consistent results by focusing attention on larger countries and industries.

Many empirical analyses first difference the levels specification (15) for estimation,

$$
\Delta \ln \left(Y_{c i t}\right)=\alpha+\beta \Delta \ln \left(P A T_{\text {eit }}^{U S}\right)+\eta_{i t}+\hat{\epsilon}_{c i t},
$$

where $\hat{\epsilon}_{c i t}=\epsilon_{c i t}-\epsilon_{c i t-1}$. The efficiency of this first-differences form versus the levels specification turns on whether the error term $\epsilon_{c i t}$ is autoregressive. If autoregressive deviations are substantial, the first-differences form is preferred; a unit-root error is fully corrected. If there is no serial correlation, however, first differencing introduces a moving-average error component. Estimations of the autoregressive parameter in the levels specification for this study find serial correlations of $0.5-0.6$, while -0.1 is evident in the first-differences form. Table $5 \mathrm{~B}$ demonstrates that the first-differences form yields similar results to the levels specification; both specifications are presented below.

\footnotetext{
${ }^{27}$ Some country to ethnicity mappings are debatable (e.g., placing Spain and Portugal with European rather than Hispanic, including the Scandinavian countries in European), as is the inclusion of communist countries. The results are robust to these marginal reclassifications. The ethnic matching procedure does not attempt to distinguish the Filipino ethnicity from Hispanic, as was done in an earlier version of this paper, but the results are very similar if the division is made.

${ }^{28}$ The five-year sum gives equal weight to each year. Regressions weighting the lagged community sizes by the coefficients from the international citation exercises yield similar results.
} 


\subsection{Foreign Country Development Controls}

The industry-year fixed effects create an empirical environment where US ethnic patenting serves as a viable metric for the strength of ethnic research communities. Moreover, the focus on within-industry variation circumvents many problems in interpretation that could arise from different industry trends (e.g., rapid high-tech growth). As the constructed panel includes multiple industries within a country, additional tests can be performed that further control for country-wide development. Table 6 undertakes three such tests, finding continued support for output expansion with stronger scientific integration.

Panel A begins by replicating the base foreign output regressions from Table 5. An immediate concern is whether the results are capturing only foreign human-capital development, which could reasonably lead to an expansion in foreign manufacturing and the emigration of researchers to the US. The National Science Foundation collects annual data on the US Ph.D. science and engineering graduates by country-of-birth. As an initial robustness check on the general human-capital development story, Panel B adds the log trend in these graduates as an additional covariate. The role of the US ethnic scientific community remains strong and significant. (These Ph.D. trends and the reverse causality question are extensively studied in Section 5's immigration analysis.)

More generally, Panels $\mathrm{C}$ and D incorporate into (15) linear country time trends and nonparametric country-year fixed effects, respectively. These additional controls remove trends common to the industries within a country, including the overall growth in each ethnicity's US research community (e.g., the strong increases in Chinese and Indian patenting in the US). For foreign output, the country effects extract national business cycles and trend manufacturing gains, countries entering trade agreements or multi-national bodies (e.g., World Trade Organization), and so on.

A positive $\beta$ coefficient in these estimations requires higher relative growth of Chinese computer research to Chinese pharmaceutical research in the US be partially correlated with higher relative output growth in China's computer industry to its pharmaceutical industry (after worldwide industry trends are removed). The triple combination of country-industry, industry-year, and country-year fixed effects is a very stringent test, as much of the variation is removed from the sample. While the positive correlations are lost in the unweighted specifications, the weighted regressions continue to support the conclusion of foreign output growth with stronger scientific integration. The decline in coefficient magnitudes suggests, moreover, that a substantial portion of the growth in each ethnicity's US research community is uniform across industries (i.e., the within-industry Chinese contributions to US computer and pharmaceutical research expand at similar rates). 


\subsection{Foreign Country Capital-Labor Controls}

Table 7 next explores the role of physical-capital development in explaining the labor productivity growth evident in Table 5. Section 2's theory only models non-durable intermediate inputs, a simplification that removes the need to track two state variables. Labor productivity grows with capital deepening as well as technology adoption, however, and it is important to distinguish the two. The UNIDO data unfortunately lack capital records for several countries. ${ }^{29}$ Thus, Panel $\mathrm{B}$ of Table 7 first re-estimates the basic labor productivity regression with the observations that have capital data. The results are close to the Full Sample replicated in Panel A, although some statistical significance is lost with the reduced sample size. Panel $\mathrm{C}$ finally incorporates into the estimating equation the contemporaneous log capital-labor ratio $K_{\text {cit }} / L_{\text {cit }}$,

$$
\ln \left(Y_{c i t} / L_{c i t}\right)=\alpha+\beta \ln \left(P A T_{\text {eit }}^{U S}\right)+\gamma \ln \left(K_{c i t} / L_{c i t}\right)+\phi_{c i}+\eta_{i t}+\epsilon_{c i t},
$$

The $\beta$ coefficients in Panel $\mathrm{C}$ are quite stable to the introduction of capital stocks, indicating that the technology transfer operates beyond just capital accumulation. ${ }^{30}$

\subsection{Sector Reallocation and Sample Composition}

The theoretical model in Section 2 delineates how the benefits of technology transfer depend upon the following country's stage of development. In the specified framework, countries with large agricultural sectors realize gains in output from technology transfer due to both labor productivity development and employment reallocation. In an alternative framework where the outside wage is held constant, the output growth comes only through labor shifts. On the other hand, following economies with full manufacturing employment only realize output growth through labor productivity enhancements.

To test these predictions, Table 4 lists the 1980 share of national employment in agriculture for each economy. ${ }^{31}$ The three smallest agricultural sectors are found in Hong Kong (1\%), Singapore (2\%), and Belgium (3\%), while the three largest sectors are India (70\%), Vietnam (73\%), and Mainland China (74\%). A modified form of (15) interacts the ethnic scientific community regressor with this pre-period agricultural share,

$$
\ln \left(Y_{c i t}\right)=\alpha+\beta \ln \left(P A T_{\text {eit }}^{U S}\right)+\gamma \ln \left(P A T_{\text {eit }}^{U S}\right) \cdot A G R \%_{c, 1980}+\phi_{c i}+\eta_{i t}+\epsilon_{c i t},
$$

\footnotetext{
${ }^{29}$ Sufficient capital data are only available for the countries noted in Table 4 and do not always cover the years listed in the UNIDO3 Panel column. Capital stocks are estimated using the perpetual inventory method with a depreciation rate of $15 \%$. Initial stocks are developed using 1980 and 1981 investments, and subsequent investments are deflated using weighted deflators taken from the NBER-CES Manufacturing Productivity Database (Bartelsman and Gray 1996). Breaks in the capital series for Chile (1987, 1988), Macao (1987), Mexico (1992, 1993), Panama (1986), and Peru (1993) are bridged in the reported regressions; the results are robust to instead dropping the years after the breaks.

${ }^{30}$ Technology improvements and investments may occur together if new technologies are embodied in machines that are purchased and installed. Additional tests suggest embodied technical change may be present, but the results are not consistent across specifications. Foreign investment may be important for realizing the productivity gains from knowledge ties to the frontier country.

${ }^{31}$ Agricultural shares are from the United Nations Statistical Division and Sun, Fulginiti, and Peterson (2003).
} 
where the main effect for the agricultural share is absorbed into the country-industry fixed effects $\phi_{c i}$. A positive $\gamma$ coefficient indicates output growth due to scientific integration is stronger in countries with larger agricultural workforces in $1980 .{ }^{32}$

Tables $8 \mathrm{~A}$ and $8 \mathrm{~B}$ report the results from these interacted regressions. In both the levels and first-differences specifications, foreign country output growth due to stronger US ethnic research integration is higher in economies with large agricultural shares in 1980. Panels B and C again disaggregate the output regression into labor productivity and employment shifts, respectively. Labor productivity gains are weaker in the less developed economies, while substantial sector reallocation through employment growth is clearly evident in Panel C. The interacted regressions thus support the model's predictions regarding the stage of development being important for how technology transfer gains are realized.

Finally, the UNIDO dataset is a diverse group of countries and industries, and it is informative to identify which observations are most responsible for the aggregate findings. Table 8 investigates this question for the patent-weighted regressions in Columns 4-8. Case studies of successful technology diffusion often focus on the computer and pharmaceutical industries, and the exceptional outcomes of Asian scientific communities in Silicon Valley are widely noted. While the industry-year effects control for the overall growth in each industry's research and output (e.g., Griliches 1994), it would be important to note if ethnic differences in high-tech industries alone are responsible for the positive correlations. The fourth column excludes the computer and pharmaceutical industries from the Full Sample and finds that while the main effect on output declines, the coefficient pattern is very similar. In general, dropping these two industries from the samples below does not significantly affect the outcomes discussed.

Chinese economies, more often than not, are also the centerpieces of technology transfer stories. Column 5 excludes Mainland China from the sample and finds very similar results. The stability of the interactions is especially comforting as Mainland China has the largest 1980 agricultural share of the sample. Unreported regressions further find that the parameter estimates do not depend significantly on the inclusion of any one country in the sample. Column 6 demonstrates, however, that excluding the full Chinese ethnicity can be important. In the both the levels and first-differences specifications, the main effect of output increasing is lost due to opposite movements in labor productivity and employment. Given that the Chinese grouping includes three of the four Asian "tiger" economies (i.e., Hong Kong, Singapore, and Taiwan) and Mainland China, it is not too surprising that the main effect is sensitive to their inclusion. Reassuringly for the sector reallocation finding, the interactions remain in their predicted directions in both specifications despite excluding the three most extreme economies.

The Full Sample also includes several industrialized economies that are undertaking extensive R\&D themselves. For example, Japanese inventors living in the US, who are well identified with

\footnotetext{
${ }^{32}$ Both of the main effects are demeaned prior to the interaction to restore the $\beta$ coefficient to close to its base level.
} 
the ethnic-name database, patented less than 10,000 inventions from 1985-1997; almost 300,000 patents were awarded to Japanese inventors living outside of the US during this period. ${ }^{33}$ Positive correlations of foreign productivity growth to US ethnic research may simply be capturing reverse technology flows, intra-company patenting, or defensive patenting from these advanced economies. Exploring this issue, Columns 7 excludes Japan, European countries, and Russia from the Full Sample. The sharper contrast of the Chinese and Hispanic economies increases the productivity main effects, but the overall coefficient pattern is again evident. Finally, the UNIDO descriptive statistics noted that European and Hispanic countries each account for about $40 \%$ of the sample. The last columns drops Hispanic countries, finding results similar to the Full Sample estimations, although the output interaction is diminished.

In summary, the sample composition adjustments find positive benefits to scientific integration with the US are evident throughout the panel studied. While manufacturing output growth is pervasive, it is especially strong in economies with large agricultural sectors that facilitate sector reallocation. In countries with minimal agricultural employment, output growth comes through labor productivity gains.

\section{Exogenous Changes from US Immigration Reforms}

While OLS regressions establish partial correlations present in the data, they frequently fail to identify causal relationships due to the endogenous relationships between outcomes or due to omitted variable biases. Domestic human-capital developments in Chinese economies, for example, could lead to both higher productivity and output growth at home and the export of scientists to the US. Alternatively, R\&D in Japan might be responsible for the growth of its Asian neighbors and feed into higher US research output. Despite the strong fixed-effect specifications employed, further exercises can aid in the interpretation of the positive outcomes evident in patent-based regressions.

The earlier model helps understand and address these concerns. Consider the initial transition from the equilibrium described in Section 2 following an industrialization push in China. China's government temporarily subsidizes invention until condition (9) no longer holds. As $I>\tilde{I} \Psi[M / \tilde{I}]\left(\tilde{H}^{C}\right)^{\beta}$, it is more profitable for researchers in China to invent rather than imitate; China's output growth and sector reallocation are now driven solely by domestic innovations. In the US, Chinese researchers switch from inventing to imitating, as the latter is initially very easy (i.e., $\Psi[0]$ is high). If international property rights are weak, so that US Chinese can register their imitations with the US patent office, a positive $\beta$ coefficient will be found in the core estimating equations even though China's manufacturing gains no longer depend on its research community in the US. In fact, data trends will show contemporaneous accelerations in

\footnotetext{
${ }^{33}$ The estimates are sums over inventor ethnicity percentages at the patent level. Japanese inventors are associated with more patents due to multiple inventors.
} 
the growth of foreign output and US ethnic patenting. ${ }^{34}$

The US population of Chinese researchers is a foothold for establishing greater confidence in the direction of technology flows as they only influence China's development through their transmission of knowledge regarding US innovations. If the size of this research population is exogenously determined by immigration restrictions, a reduced-form strategy for the size of the ethnic research community can be developed within the quotas system. US immigration law does not control the population size of foreigners in the US, but it does control the inflow of new immigrants. Define the quota on Chinese inflows of researchers to the US to be QUOT $A_{R_{C}, t}$. Assuming that only the previous three years of immigration matter for a research stock ${ }^{35}$, a reduced-form immigration estimator for ethnic scientific integration to the US is modelled as

$$
\ln \left(I M M_{R_{C}, t}^{R F}\right)=\ln \left[\sum_{s=1}^{5}\left(Q \operatorname{UOT} A_{R_{C}, t-s}+\text { QUOT } A_{R_{C}, t-s-1}+\text { QUOT } A_{R_{C}, t-s-2}\right)\right] .
$$

The summation over the previous five years maintains the human-capital stock modelling technique employed with the ethnic patenting dataset. This section designs and implements an empirical version of (17) using exogenous changes in US immigration quotas.

Before proceeding, it is worth outlining why the US quotas are employed for a reduced-form estimator rather than in an instrumental-variables specification. The unobserved regressor in this study is the human-capital stock of each ethnicity with respect to US technologies. The patent metrics employed in Section 4 proxy, albeit imperfectly, for this scientific integration. Immigration quotas directly influence the size of ethnic research communities in the US, and thus the unobserved human-capital stocks. Scientific bonds, however, can operate through other channels besides formal patenting and the informal or tacit knowledge of new technologies that the patent metrics represent. As the exclusion restriction required for two-stage least squares does not hold, coefficient estimates from using the immigration estimator as an instrumental variable would be upward biased. The reduced-form approach, however, offers a direct check for the patent-based findings using exogenous changes in the populations of immigrant researchers living in the US.

\footnotetext{
${ }^{34}$ China's economy still depends on previously imitated products, as well as new inventions. How the system evolves from this initial disturbance depends on the relative populations of the Chinese researchers in the US and China. If the US Chinese group is sufficiently small, they will continue imitating a large invention stock developed abroad forever, and the Chinese human-capital stock with respect to US inventions will decline to zero. China's researchers will continue inventing, and the gap between China's researcher productivity for invention versus imitation will become entrenched. On the other hand, if the US Chinese research community is sufficiently large relative to China's, the declining imitation productivity will require at least some US Chinese resume direct invention to maintain full employment. In this scenario, the initial reverse technology flows yield to either a sustained mixing strategy, with Chinese researchers in both countries inventing and imitating, or the US Chinese resuming the leading role.

${ }^{35}$ The immigration reform examined below focuses on a very sharp surge in immigration that makes this assumption reasonable.
} 


\subsection{The Immigration Act of $\mathbf{1 9 9 0}$}

The disproportionate influence of immigrant scientists and engineers (ISEs) in the US is staggering: while immigrants account for $10 \%$ of the US working population, they represent $25 \%$ of the US science and engineering workforce and $50 \%$ of those with doctorates. Even looking within the Ph.D. level, immigrant researchers have an exceptional contribution to science as measured by Nobel Prizes, election to the National Academy of Sciences, patent citation counts, and so on. ${ }^{36}$ Yet, the US immigration system significantly restricted the inflow of ISEs from certain nations prior to its reform with the Immigration Act of 1990 (1990 Act).

US immigration law applies two distinct quotas to numerically restricted immigrants. ${ }^{37}$ Both of these quotas were increased by the 1990 Act, and their combined change dramatically released pent-up immigration demand from researchers in constrained countries. The first quota governs the annual number of immigrants admitted per country. This quota is uniform across nations, and the 1990 Act increased the limit from 20,000 to approximately 25,620. ${ }^{38}$ Larger nations are more constrained by country quotas than smaller nations and benefited most from these higher admission rates. Second, separately applied quotas govern the relative admissions of familybased versus employment-based immigrants. Prior to the 1990 Act, the quotas substantially favored family-reunification applications $(216,000)$ to employment applications $(54,000)$. The 1990 Act shifted this priority structure by raising employment-based immigration to 120,120 ( $20 \%$ to $36 \%$ of the total) and reducing family-based admissions to $196,000 .{ }^{39}$ Moreover, the relative admissions of high-skilled professionals to low-skilled workers significantly increased within the employment-based admissions.

The uniform country quotas and weak employment preferences constrained high-skilled immigration from large nations, and long waiting lists for Chinese, Indian, and Filipino applicants formed in the 1980s. When the 1990 Act simultaneously raised both of these quotas, the number of ISEs entering the US dramatically increased. Figures 4 and 5 use records from the Immigration and Naturalization Service (INS) to detail the response. Figure 4 plots the number of ISEs granted permanent residency in the US from 1983-1997 for selected ethnicities (summed over countries within each ethnicity). Prior to the 1990 Act, no trends are evident in ISE immigration. The 1990 Act took effect in October 1991, and a small increase occurred in the final three months of 1991 for Chinese and Indian ISEs. Immigration further surged in 1992-1995 as the pent-up demand was released. Figure 5, on the other hand, shows low-skilled

\footnotetext{
${ }^{36}$ For example, Stephan and Levin (2001), Burton and Wang (1999), Johnson (1998, 2001), and Streeter (1997).

${ }^{37}$ US immigrants are admitted through numerically restricted categories, governed by the quotas discussed in this section, and numerically unrestricted categories (e.g., immediate relatives of US citizens). The reduced-form estimator centers on the numerically restricted categories that admit $75 \%$ of ISEs (versus $43 \%$ of all immigrants). Jasso, Rosenzweig, and Smith (1998) outline US immigration policy and the 1990 Act; they further discuss behavioral responses to changes in quotas. ISE inflows through the unrestricted categories are stable in the years surrounding the 1990 reform.

${ }^{38}$ The worldwide ceiling for numerically restricted immigration now fluctuates slightly year-to-year based on past levels; maximum immigration from a single country is limited to $7 \%$ of the worldwide ceiling.

${ }^{39}$ The employment limit increased to 140,000 , but 120,120 corresponds to the previously restricted categories.
} 
immigration during the same period. While Chinese and Indian immigration are substantially higher than Hispanic immigration for science and engineering, the opposite is true for low-skilled immigration. Moreover, low-skilled immigration did not respond to the 1990 Act. ${ }^{40}$

The extremely large Chinese response and sharp decline is partly due to a second law that slightly modified the timing of the 1990 Act's reforms. Following the Tiananmen Square crisis in June 1989, Chinese students present in the US from the time of the crisis until May 1990 were permitted to remain in the US until at least 1994 if they so desired. The Chinese Student Protection Act (CSPA), signed in 1992, further granted this cohort the option to change from temporary to permanent status during a one-year period lasting from July 1993 to July 1994. The CSPA stipulated, however, that excess immigration from the CSPA, over Mainland China's numerical limit, be deducted from later admissions. The timing of the CSPA partly explains the 1993 spike, and the ability of graduating Chinese science and engineering students to remain in the US in 1990 should factor into the timing of the reduced-form estimator.

Finally, National Science Foundation surveys of graduating science and engineering doctoral students, the group most important for developing human capital with respect to US innovations, confirm the strong responses evident in the INS data. The questionnaires ask foreign-born Ph.D. students in their final year of US study about their plans after graduation. Figure 6 exhibits the percentage intending to remain in the US for available countries. The $60 \%$ to $90 \%$ jump for Mainland China from 1990 to 1992 is striking. Substantial increases are also apparent for India and Western Europe.

\subsection{Immigration Responses}

The reduced-form strategy exploits differences in the extent to which countries were affected by the 1990 reform. It is inappropriate, however, to use the outcomes exhibited in Figures 4-6 to determine treatment and control groups. A proper designation of the affected countries requires a more formal analysis of researcher immigration responses to the legislation change. Let $I S E \%_{c t_{0}}^{A d m}$ be the mean ISE arrivals from country $c$ divided by an approximate country-level numerical limit for employment-based workers during the 1983-1990 pre-period. The theoretical numerical limit is taken to be the 20,000 country limit multiplied by the $20 \%$ worldwide allocation given to employment-based applications (i.e., 54,000/270,000). ${ }^{41}$

Define $P O S T_{t}$ as a indicator variable taking the value of zero from 1983-1990 and one for 1991 and after (i.e., the 1990 Act's effective date). Regressing annual ISE admissions $I S E_{c t}^{A d m}$

\footnotetext{
${ }^{40}$ Immigration trends are developed from immigrant-level INS records. The permanent residency admissions include ISEs already working in the US on temporary visas. The trends for "new arrival" ISE are very similar. Temporary visas can only be renewed once, so the total shift in ISE population should include workers gaining permanent residency. The analysis below does not depend on this distinction. Science and engineering categories are defined as Engineers, Natural Scientists, and Mathematical and Computer Scientists; low-skilled categories are Administrative Support, Farming, Laborer, Precision Production and Repair, Service, and Sales occupations.

${ }^{41}$ The total employment immigration column in Table 9 demonstrates the theoretical limit works quite well. The scientific percentages are even larger than they initially seem since family members of employment-based admissions count towards the two quotas. The specific years selected for the pre-period are not important.
} 
on an interaction of $I S E \%_{c_{0}}^{A d m}$ with $P O S T_{t}$ quantifies the immigration response of constrained countries,

$$
I S E_{c t}^{A d m}=\alpha+\gamma I S E \%_{c t_{0}}^{A d m} \cdot P O S T_{t}+\phi_{c}+\eta_{t}+\epsilon_{c t} .
$$

The main effect for $I S E \%_{c t_{0}}^{A d m}$ is absorbed by the country fixed effects $\phi_{c}$, along with levels differences between nations in US immigration. The year effects $\eta_{t}$ remove aggregate changes in US permanent residency admissions and control for the main effect of $P O S T_{t}$.

The $\gamma$ coefficient in (18) will be positive and significant if raising the two numerical limits spurred ISE immigration from previously constrained countries (i.e., high values of $I S E \%_{c t_{0}}^{A d m}$ ). Table 9 shows this to be true, and economies with high values of $I S E \%_{c t_{0}}^{A d m}$ become the treatment group regardless of actual responses. From the waiting list and 1983-1990 flow data presented in Table 9, the treated groups are determined to be India, Mainland China, the Philippines, and Taiwan. $^{42}$ The reduced-form immigration estimator (17) then takes the form

$$
\ln \left(I M M_{c i t}^{R F}\right)=\ln \left[\sum_{s=1}^{5}\left(Q U O T A_{c, t-s}^{E f f}+Q U O T A_{c, t-s-1}^{E f f}+Q U O T A_{c, t-s-2}^{E f f}\right)\right]
$$

where QUOT $A_{c t}^{E f f}$ is the effective quota for country $c$ in year $t$. Raising the numerical ceilings did not change the effective quotas for nations unconstrained by the former immigration regime (i.e., low $I S E \%_{c t_{0}}^{A d m}$ ), and their effective quotas are held constant at the pre-reform theoretical limit. For constrained countries with high $I S E \%_{c t_{0}}^{A d m}$ values, the effective quota increases to reflect both the higher country limit of 25,600 and the larger employment preference allocation of $36 \%$ (i.e., 120,120/336,000). This quota increase occurs in 1991, and the shift is moved forward to 1990 for Mainland China to account for the CSPA.

This simple reduced-form approach abstracts from several issues: return migration (e.g., Taiwanese scientists in the mid 1990s), occupational or industry changes by ISEs, second-generation immigrant demographics, shifts in research productivity, and others. If these types of concerns are overwhelming, regressions of US ethnic patenting on the reduced-form estimator will yield weak coefficients. The right-hand side of Table 9 shows instead that they are quite strong despite the design's simplicity. However, two more serious reservations regarding the estimator should be addressed before viewing the results.

First, the quota change affected all skilled workers seeking admission into the US, not just researchers, and the impact of other occupations should be considered. The reduced-form estimator should only influence foreign manufacturing output and productivity through the development of human capital with respect to US technologies. Most skilled occupations can be dismissed immediately, yet Table 9 shows immigration of business executives and lawyers also increased after the 1990 Act. It is possible this business group might influence foreign output

\footnotetext{
${ }^{42}$ Hong Kong is not included in the treatment group as its immigration status was not affected by the 1990 reform. The main results are robust to instead defining the treatment group at the ethnicity level, although the additional variation inherent in the country-level approach enhances performance in falsification exercises.
} 
growth through better sales contacts or higher foreign investment independent of technology transfer. The relative volumes argue against this concern, as the size of the influx relative to the existing base for advanced-degree researchers dwarfs other occupations. The planned inflow of Chinese science and engineering Ph.D.s for 1991-1995, as measured by the NSF surveys, would have doubled the existing Chinese-born Ph.D. stock in the 1990 Census. The business inflow over this period is only about $20 \%$ of the 1990 stock.

A second liability is that the reduced-form estimator may be correlated with other factors. Here, the simplicity of its design is a concern. While determined by the data, the quotas technique only distinguishes between the treatment group (i.e., India, Mainland China, the Philippines, and Taiwan) and the remainder of the sample. Other changes occurring around 1991 that affect the output growth of the treatment group differentially from the control group could confound the analysis. Figure 7 gives some weight to this omitted variable concern for Mainland China. Mainland China was on a clear upward trend in science and engineering Ph.D. graduates in the US prior to the 1990 Act. ${ }^{43}$ A similar expansion of researchers at home is likely and may have directly impacted manufacturing development. These concerns are evaluated empirically below.

\subsection{Reduced-Form Results}

The reduced-form regressions for 1985-1997 mirror the patent-based approach,

$$
\ln \left(Y_{c i t}\right)=\alpha+\beta \ln \left(I M M_{c t}^{R F}\right)+\phi_{c i}+\eta_{i t}+\epsilon_{c i t},
$$

with $\ln \left(I M M_{c t}^{R F}\right)$ defined by (19). Table 10 exhibits the main results in a format similar to that of Table 5. The reduced-form estimator suggests foreign output increases with an elasticity of 0.3-0.4 to higher ethnic research in the US. While the $\beta$ coefficients should not be directly compared to the patent-based approach, the interpretation that greater scientific integration with the US boosts foreign manufacturing development is supported. The lower variance in Table 10's estimates across weighting schemes reflects the country-level design of the immigration estimator.

In contrast to the patent-based results, Panels B and C find output growth comes mainly through higher employment levels rather than labor productivity gains. This difference is easily explained with the sector reallocation model. Three of the four treated economies had large agricultural sectors in 1980 that supported significant expansions in employment (Taiwan is the one exception at 8\%). The immigration estimator contrasts the outcomes in these economies with the control sample and thus emphasizes the sector reallocation process. The patent-based regressions, on the other hand, paid greater attention to the outcomes of Hong Kong, Macao, and Singapore through the application of the US Chinese ethnic patenting series to all economies

\footnotetext{
${ }^{43}$ On a logarithmic scale, Figure 7 exhibits a smooth trend for Mainland China from 1985-1991 with a marginal decrease in the growth rate thereafter.
} 
within the Chinese ethnicity. Without an agricultural sector from which to draw labor, these economies experienced sharper labor productivity gains.

Table 11 next turns to robustness checks on the output growth finding, with the first row simply replicating the core regression set. As a test of the foreign human-capital development story, Panel B incorporates Figure 7's trends in foreign graduates from US science and engineering Ph.D. programs. Both the levels and first-differences specifications hold up well in the augmented specification. Given the specific concern regarding Figure 7's trend growth in Mainland China's Ph.D. graduates, it is reassuring that this country can be again excluded in Panel $\mathrm{C}$ with only minor shifts in the outcomes. As before, the results are also robust to dropping any other country, the computer and drug industries, the full Chinese ethnicity, advanced or Hispanic economies, and so forth. ${ }^{44}$

Finally, Panel D incorporates a linear ethnic time trend that removes the trend growth in both the foreign country output and the US immigration estimator. By doing so, the framework emphasizes the discontinuity of the 1990 reform for the identification of the $\beta$ parameter. Despite losing about about half of their size, the coefficients remain economically and statistically significant in the augmented specification. Given the stringency of this test, this strong performance provides confidence against the estimator reflecting a spurious correlation.

Table 12 completes the immigration analysis by incorporating into (20) two counterfactual estimators that move the 1991 effective date of the immigration reform earlier to 1987 or later to 1995. The results with the 1987 counterfactual are mixed. Encouragingly, the coefficients on the true estimator retain $60 \%-90 \%$ of their value and are still statistically different from zero. Moreover, the standard errors for the placebo estimators are 100\%-300\% larger than those of the true estimator, and the placebo estimators are not statistically significant. The coefficient estimates on the 1987 estimator, however, are of similar magnitude to the true reform, and it cannot be rejected that the coefficients are the same. Panel E, on the other hand, shows better performance with the 1995 counterfactual. Table 12 thus supports the conclusion of stronger scientific integration leading to foreign output growth, but also highlights that the estimated elasticity with the immigration estimator may be partly capturing an earlier differential change for the treatment group.

Establishing the causal direction of international technology flows is a very daunting task. The reduced-form quotas estimator offers more confidence than the patent-based approach that

\footnotetext{
${ }^{44}$ The robustness of the Full Sample results to excluding India is important. The INS quotas design does not consider shifts in the US ethnic populations of temporary workers (e.g., the H-1B program). The temporary visa program up to the mid-1990s looked quite different from today. Fewer visas were issued, and the most significant occupation and country were medical professionals and the Philippines, respectively. An explosion in Indian temporary workers, mostly for systems analysis and computer programming jobs, began in the 1990s. From 1989-1999, India's share of temporary visas issued rose from 9\% to 48\% (e.g., Lowell 2000 ).

Temporary visas can only be renewed once, for a maximum stay of six years, so long-term growth in ethnic research communities requires permanent immigration. Outside of India, the trends for temporary visas are fairly stable for the period studied, and the science and engineering component appears small compared to permanent residency changes. While the jump in India's temporary visa community could affect the final few years of the 1985-1997 period, the results do not depend on its inclusion.
} 
coefficient estimates are not determined by reverse causality (especially foreign human-capital developments). The price for this exogenous determinant, however, is the loss of industry variation that can be exploited. This reduced variation may leave the quotas estimator exposed to omitted variable biases contemporaneous to or slightly preceding the reform, although the robustness checks on sample composition, ethnic time trends, and so on strongly suggest spurious correlations are not solely responsible for the outcomes measured. Overall, the reduced-form regressions support Section 4's conclusion that foreign manufacturing output increases with stronger ethnic scientific integration to the US frontier.

\section{Conclusions}

The international diffusion of new innovations from frontier countries is necessary for broad economic development. Even when the codified details of new technologies can be easily disseminated, successful adoption may be complicated by the difficult exchange of the associated tacit knowledge. This project considers the role and importance of knowledge networks for exchanging this practical information through the observable channel of ethnicity, specifically examining the ties between US ethnic research communities and their home countries. A new tool is developed for studying the role of ethnic scientists and engineers in the US in the technology transfer process by applying an ethnic-name database to individual patent records. The resulting cross-sectional and longitudinal detail affords new insights about how knowledge diffuses across countries.

First, ethnic knowledge networks are important for explaining international patent citation patterns, with inventors living outside of the US citing US-based inventors of their own ethnicity with a $50 \%$ higher rate. The core specifications further suggest a stronger US ethnic research community boosts foreign manufacturing output with an elasticity of about 0.3. These estimates are robust to multiple specification checks, and the pattern of results is consistent with a model of sector reallocation from agriculture to manufacturing. In economies with large agricultural sectors, the manufacturing output expansions occur primarily through employment growth; in advanced economies with full manufacturing employment, the output gains are achieved via higher labor productivity. Finally, a reduced-form strategy using exogenous changes in US immigration law also finds qualitatively similar effects. These findings suggest that US ethnic communities play an important role in technology diffusion to their home countries, and more

generally that inadequate access to the tacit knowledge complementing new frontier innovations can slow development in following countries.

This paper is a first step for characterizing the complex role of tacit knowledge in technology diffusion, and two promising extensions are currently being pursued with the ethnicity approach. One project examines the relative importance of trade and FDI channels for the technology 
transfer considered in this study. ${ }^{45}$ Second, a companion study explores ethnicity's role in local knowledge diffusion within the US using the ethnic citation data. Special attention is given to high-tech clusters like Silicon Valley and Boston's Route 128, and ongoing research concentrates on the linkages between these high-tech clusters and foreign inventors (e.g., international collaborations between inventors of the same ethnicity). These extensions will further characterize how knowledge networks shape the effective technology frontier for emerging economies.

\footnotetext{
${ }^{45}$ Rauch (2001) discusses the importance of business and social networks in trade, and Rauch and Trindade (2002) demonstrate a substantial trade boost from Chinese networks. Technology diffusion is also facilitated by foreign direct investment and multinational enterprises (e.g., Branstetter 2004, Singh 2003).
} 


\section{References}

[1] Acemoglu, Daron, and Fabrizio Zilibotti, "Productivity Differences", The Quarterly Journal of Economics, 116:2 (2001), 563-606.

[2] Agrawal, Ajay, Iain Cockburne, and John McHale, "Gone But Not Forgotten: Knowledge Flows, Labor Mobility, and Enduring Social Relationships", NBER Working Paper 9950 (2004).

[3] Amsden, Alice, The Rise of "The Rest" (Oxford, UK: Oxford University Press, 2001).

[4] Atkinson, Anthony, and Joseph Stiglitz, "A New View of Technological Change", The Economic Journal, 79:315 (1969), 573-578.

[5] Banerjee, Abhijit, and Andrew Newman, "Occupational Choice and the Process of Development", The Journal of Political Economy, 101:2 (1993), 274-298.

[6] Barro, Robert, and Xavier Sala-i-Martin, Economic Growth (Cambridge: MIT Press, 1995).

[7] Bartelsman, Eric, and Wayne Gray, "The NBER Manufacturing Productivity Database", NBER Technical Working Paper 205 (1996).

[8] Bertrand, Marianne, Esther Duflo, and Sendhil Mullainathan, "How Much Should We Trust Difference in Differences Estimates?", The Quarterly Journal of Economics, 119:1 (2004), 249-275.

[9] Borjas, George, "Do Foreign Students Crowd Out Native Students from Graduate Programs?", NBER Working Paper 10349 (2004).

[10] Branstetter, Lee, "Is Foreign Direct Investment a Channel of Knowledge Spillovers? Evidence from Japan's FDI in the United States", Working Paper (2004).

[11] Branstetter, Lee, and Yoshiaki Ogura, "Is Academic Science Driving a Surge in Industrial Innovation? Evidence from Patent Citations", NBER Working Paper 11561 (2005).

[12] Burton, Lawrence, and Jack Wang, "How Much Does the U.S. Rely on Immigrant Engineers?", National Science Foundation SRS Issue Brief (1999).

[13] Coe, David, and Elhanan Helpman, "International R\&D Spillovers", European Economic Review, 39 (1995), 859-887.

[14] Coe, David, Elhanan Helpman, and Alexander Hoffmaister, "North-South R \& D Spillovers", The Economic Journal, 107:440 (1997), 134-149.

[15] Dumais, Guy, Glenn Ellison, and Edward Glaeser, "Geographic Concentration as a Dynamic Process", CES Working Paper 98-3 (1997).

[16] Eaton, Jonathan, and Samuel Kortum, "International Technology Diffusion: Theory and Measurement", International Economic Review, 40:3 (1999), 537-570.

[17] Feinstein, Charles, and Christopher Howe, ed., Chinese Technology Transfer in the $1990 \mathrm{~s}$ (Cheltenham, UK: Edward Elgar, 1997).

[18] Freeman, Richard, "Does Globalization of the Scientific/Engineering Workforce Threaten U.S. Economic Leadership?", NBER Working Paper 11457 (2005). 
[19] Griliches, Zvi, "Productivity, R\&D, and the Data Constraint", The American Economic Review, 84:1 (1994), 1-23.

[20] Griliches, Zvi, "Patent Statistics as Economic Indicators: A Survey", Journal of Economic Literature, 28:4 (1990), 1661-1707.

[21] Grossman, Gene, and Elhanan Helpman, Innovation and Growth in the Global Economy (Cambridge, MA: MIT Press, 1991).

[22] Hall, Bronwyn, "Exploring the Patent Explosion", NBER Working Paper 10605 (2004).

[23] Hall, Bronwyn, Adam Jaffe, and Manuel Trajtenberg, "The NBER Patent Citation Data File: Lessons, Insights and Methodological Tools", NBER Working Paper 8498 (2001).

[24] Harris, John, and Michael Todaro, "Migration, Unemployment, and Development: A TwoSector Analysis", The American Economic Review, 60:1 (1970), 126-142.

[25] Helpman, Elhanan, "R\&D and Productivity: The International Connection", in Razin, Assaf, and Efraim Sadka, ed., The Economics of Globalization (Cambridge, UK: Cambridge University Press, 1999).

[26] Hu, Albert, and Adam Jaffe, "Patent Citations and International Knowledge Flow: The Cases of Korea and Taiwan", International Journal of Industrial Organization, forthcoming 2004.

[27] Jacobs, Jane, The Economy of Cities (New York, NY: Vintage Books, 1970).

[28] Jaffe, Adam, and Manuel Trajtenberg, "International Knowledge Flows: Evidence from Patent Citations", Economics of Innovation and New Technology, 8 (1999), 105-136.

[29] Jaffe, Adam, Manuel Trajtenberg, and Michael Fogarty, "Knowledge Spillovers and Patent Citations: Evidence from a Survey of Inventors", The American Economic Review, 90:2 (2000), 215-218.

[30] Jaffe, Adam, Manuel Trajtenberg, and Rebecca Henderson, "Geographic Localization of Knowledge Spillovers as Evidenced by Patent Citations", The Quarterly Journal of Economics, 108:3 (1993), 577-598.

[31] Jasso, Guillermina, Mark Rosenzweig, and James Smith, "The Changing Skill of New Immigrants to the United States: Recent Trends and Their Determinants", NBER Working Paper 6764 (1998).

[32] Johnson, Daniel, "150 Years of American Invention: Methodology and a First Geographic Application", Wellesley College Economics Working Paper 99-01 (1999). Data currently reside at http://faculty1.coloradocollege.edu/ djohnson/uships.html.

[33] Johnson, Jean, "Statistical Profiles of Foreign Doctoral Recipients in Science and Engineering: Plans to Stay in the United States", National Science Foundation SRS Special Report (1998).

[34] Johnson, Jean, "Human Resource Contribution to U.S. Science and Engineering From China", National Science Foundation SRS Issue Brief (2001).

[35] Kannankutty, Nirmala, and R. Keith Wilkinson, "SESTAT: A Tool for Studying Scientists and Engineers in the United States", National Science Foundation SRS Special Report (1999). 
[36] Kapur, Devesh, and John McHale, "Sojourns and Software: Internationally Mobile Human Capital and High-Tech Industry Development in India, Ireland, and Israel", Working Paper (2003).

[37] Keller, Wolfgang, "Trade and the Transmission of Technology", Journal of Economic Growth, 7 (2002a), 5-24.

[38] Keller, Wolfgang, "Geographic Localization of International Technology Diffusion", The American Economic Review, 92:1 (2002b), 120-142.

[39] Keller, Wolfgang, "International Technology Diffusion", Journal of Economic Literature, $42: 3$ (2004), 752-782.

[40] Kerr, William, "The Ethnic Composition of US Inventors", Working Paper (2005).

[41] Kim, Jinyoung, and Gerald Marschke, "Accounting for the Recent Surge in U.S. Patenting: Changes in R\&D Expenditures, Patent Yields, and the High Tech Sector", Economics of Innovation and New Technologies, 13:6 (2004), 543-558.

[42] Kim, Linsu, Imitation to Innovation (Boston, MA: Harvard Business School Press, 1997).

[43] Kortum, Samuel, and Joshua Lerner, "Assessing the Contribution of Venture Capital to Innovation", RAND Journal of Economics, 31:4 (2000), 674-692.

[44] Lester, Richard, and Michael Piore, Innovation: The Missing Dimension (Cambridge, MA: Harvard University Press, 2004).

[45] Lim, Youngil, Technology and Productivity (Cambridge, MA: MIT Press, 1999).

[46] Lowell, B. Lindsay, "H1-B Temporary Workers: Estimating the Population", The Center for Comparative Immigration Studies Working Paper 12 (2000).

[47] Mankiw, N. Gregory, David Romer, and David Weil, "A Contribution to the Empirics of Economic Growth", The Quarterly Journal of Economics, 107:2 (1992), 407-437.

[48] Marshall, Alfred, Principles of Economics (London, UK: MacMillan and Co., 1890).

[49] Nelson, Richard, and Edmund Phelps, "Investment in Humans, Technological Diffusion, and Economic Growth", The American Economic Review, 56:1 (1966), 69-75.

[50] OECD, Science and Technology Indicator Scoreboard (2004).

[51] Parente, Stephen, and Edward Prescott, "Barriers to Technology Adoption and Development", The Journal of Political Economy, 102:2 (1994), 298-321.

[52] Peri, Giovanni, "Determinants of Knowledge Flows and their Effect on Innovation", Working Paper (2004).

[53] Piore, Michael, "The Limits of the Division of Labor in Design and the Prospects for OffShore Software Development in Mexico", Working Paper (2004).

[54] Polanyi, Michael, Personal Knowledge: Towards a Post-Critical Philosophy, (Chicago, IL: University of Chicago Press, 1958).

[55] Polanyi, Michael, The Tacit Dimension (Garden City, NY: Doubleday \& Company, 1966). 
[56] Rauch, James, "Business and Social Networks in International Trade", Journal of Economic Literature, 39 (2001), 1177-1203.

[57] Rauch, James, and Vitor Trindade, "Ethnic Chinese Networks in International Trade", The Review of Economics and Statistics, 84:1 (2002), 116-130.

[58] Riveria-Baitz, Luis, and Paul Romer, "Economic Integration and Endogenous Growth", The Quarterly Journal of Economics, 106:2 (1991), 531-555.

[59] Romer, Paul, "Increasing Returns and Long-Run Growth", The Journal of Political Economy, 94:5 (1986), 1002-1037.

[60] Romer, Paul, "Endogenous Technological Change", The Journal of Political Economy, 98:5 (1990), S71-S102.

[61] Rosenthal, Stuart, and William Strange, "Geography, Industrial Organization, and Agglomeration", The Review of Economics and Statistics, 85:2 (2003), 377-393.

[62] Saxenian, AnnaLee, with Yasuyuki Motoyama and Xiaohong Quan, Local and Global Networks of Immigrant Professionals in Silicon Valley (San Francisco, CA: Public Policy Institute of California, 2002a).

[63] Saxenian, AnnaLee, "Silicon Valley's New Immigrant High-Growth Entrepreneurs", Economic Development Quarterly, 16:1 (2002b), 20-31.

[64] Scherer, Frederic, "Using Linked Patent Data and R\&D Data to Measure Technology Flows," in Griliches, Zvi (ed.) $R$ \& $D$, Patents and Productivity (Chicago, IL: University of Chicago Press, 1984).

[65] Silverman, Brian, "Technological Resources and the Direction of Corporate Diversification: Toward an Integration of the Resource-Based View and Transaction Cost Economics", Management Science, 45:8 (1999), 1109-1124.

[66] Singh, Jasjit, "Multinational Firms and International Knowledge Diffusion: Evidence from Patent Citation Data", Working Paper (2003).

[67] Stephan, Paula, and Sharon Levin, "Exceptional Contributions to US Science by the Foreign-Born and Foreign-Educated", Population Research and Policy Review, 20:1 (2001), 59-79.

[68] Streeter, Joanne, "Major Declines in Admissions of Immigrant Scientists and Engineers in Fiscal Year 1994", National Science Foundation SRS Issue Brief (1997).

[69] Sun, Ling, Lilyan Fulginiti, and Wesley Peterson, "Accounting for Agricultural Decline with Economic Growth in Taiwan", Working Paper (2003).

[70] Thompson, Peter, "Patent Citations and the Geography of Knowledge Spillovers: What do Patent Examiners Know?", Working Paper (2004).

[71] Thompson, Peter, and Melanie Fox-Kean, "Patent Citations and the Geography of Knowledge Spillovers: A Reassessment", The American Economic Review, forthcoming (2004).

[72] Wooldridge, Jeffrey, Econometric Analysis of Cross Section and Panel Data (Cambridge, MA: MIT Press, 2002). 
Figure 1: Transition Path Simulations for China
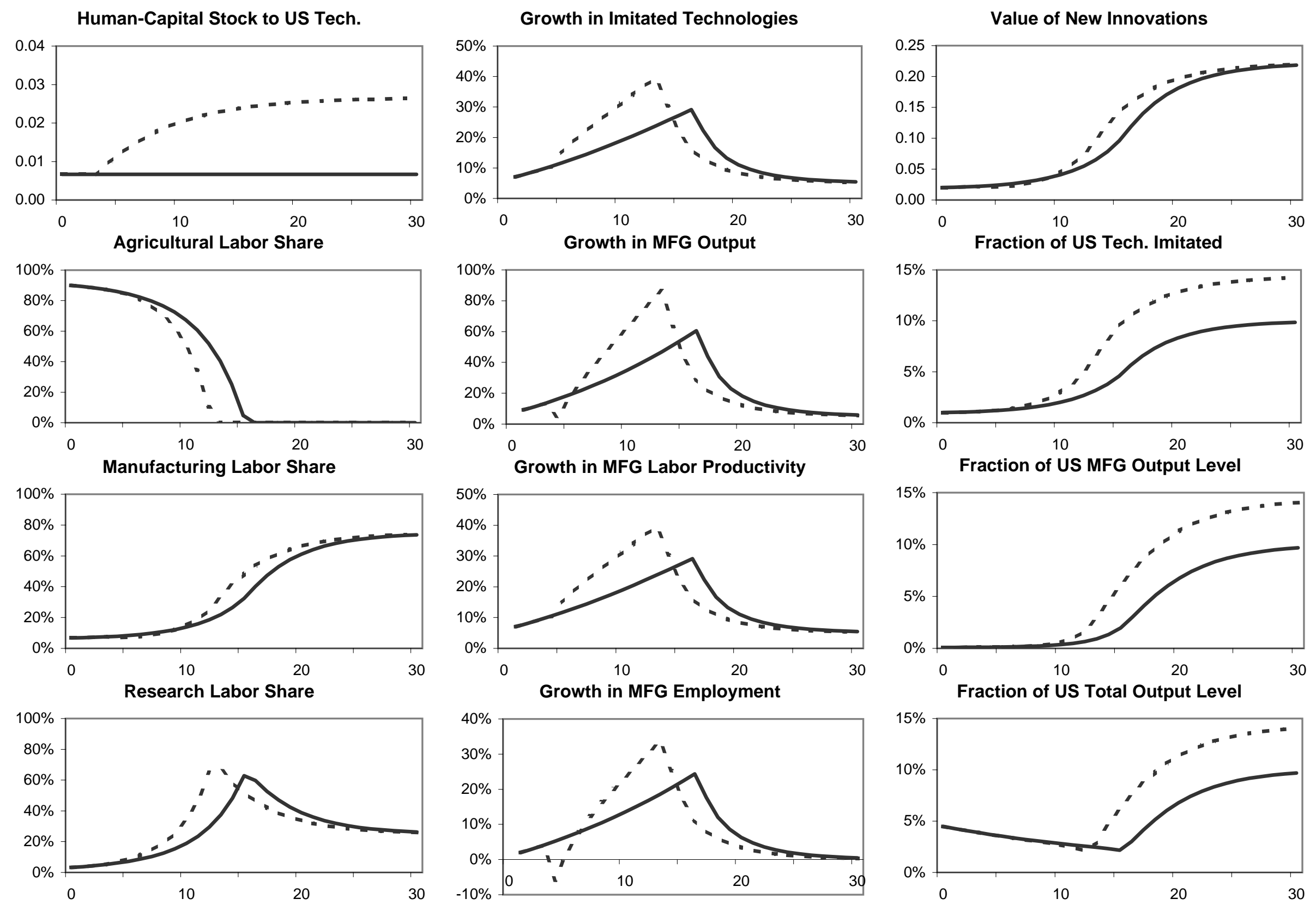
Figure 2: US Ethnic Patenting

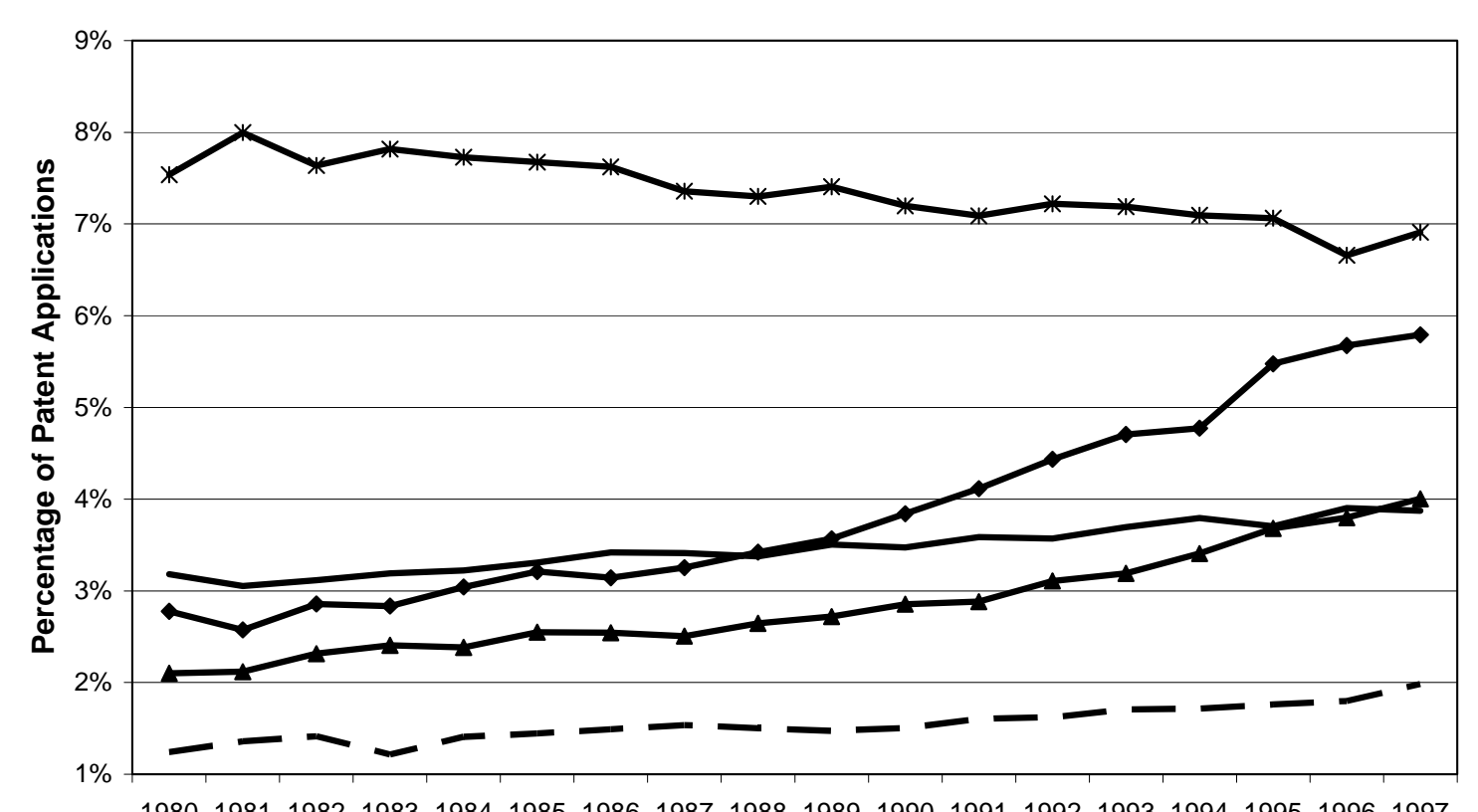

198019811982198319841985198619871988198919901991199219931994199519961997

$\longrightarrow$ Chinese $\rightarrow$ European $\longrightarrow$ Indian $\longrightarrow$ Hispanic $\longrightarrow$ 'Russian

Figure 3: Ethnic Share by Technology

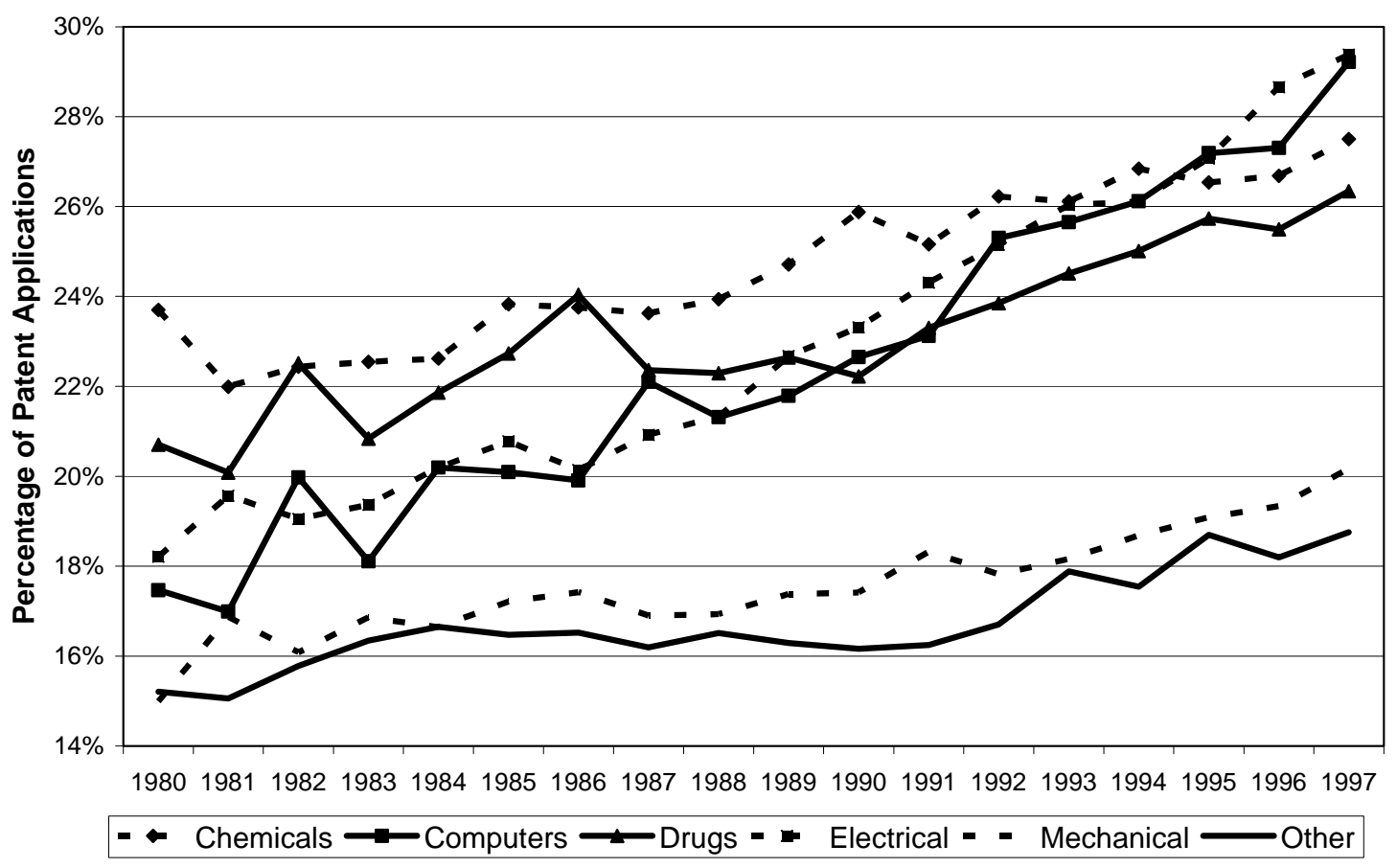


Figure 4: Science \& Engineering Immigration

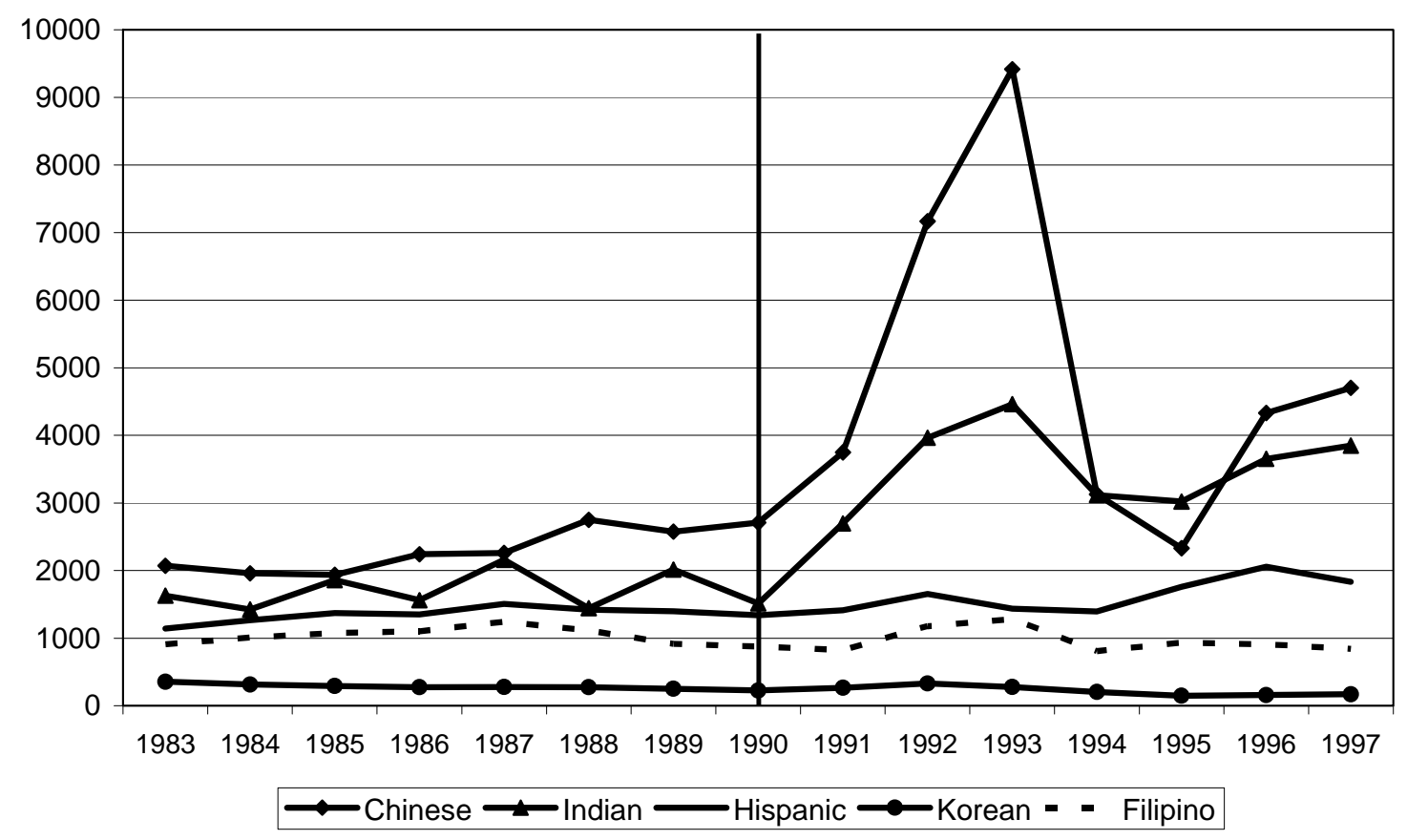

Figure 5: Low-Skilled Immigration

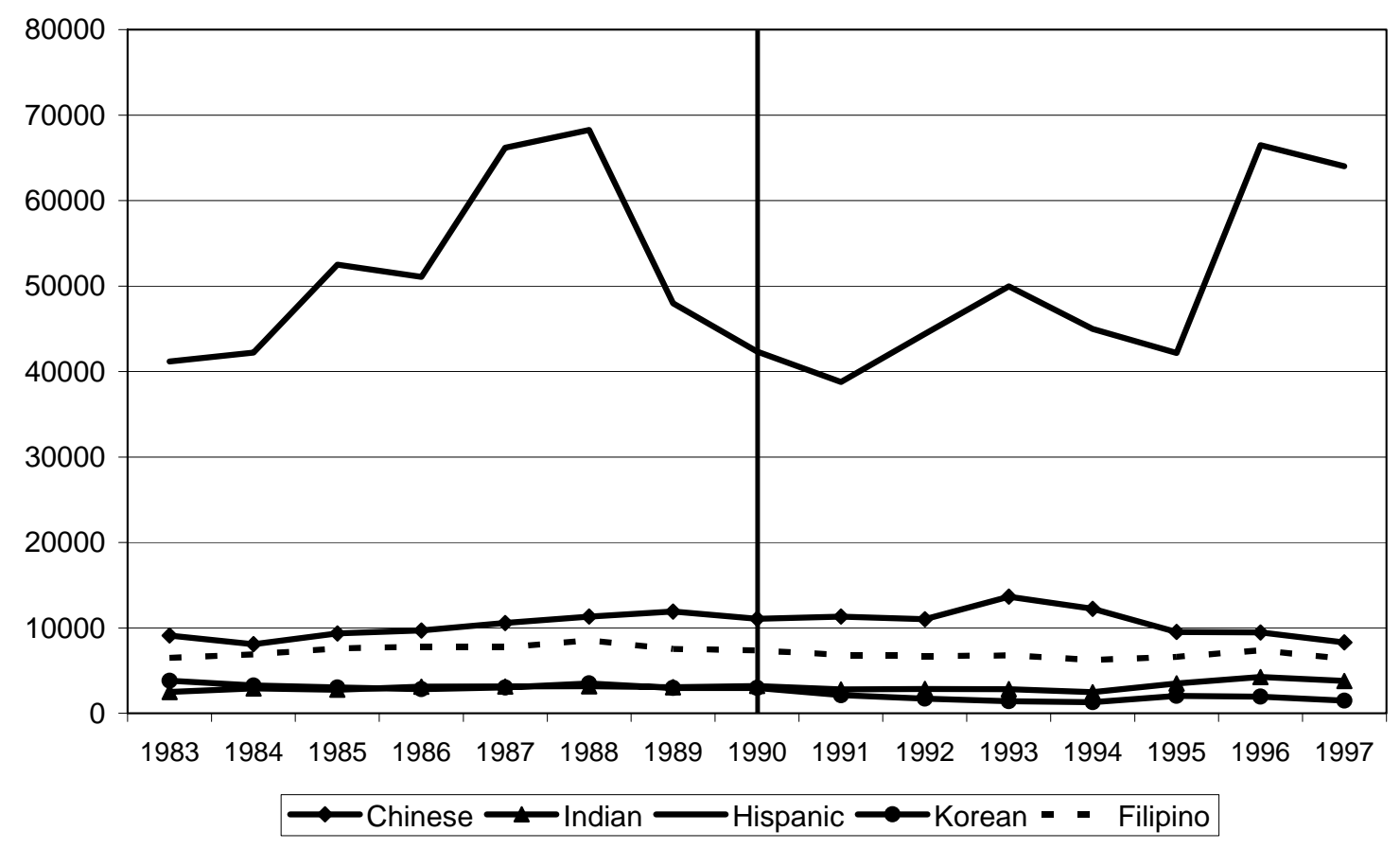


Figure 6: US SE Ph.D. Graduates Staying

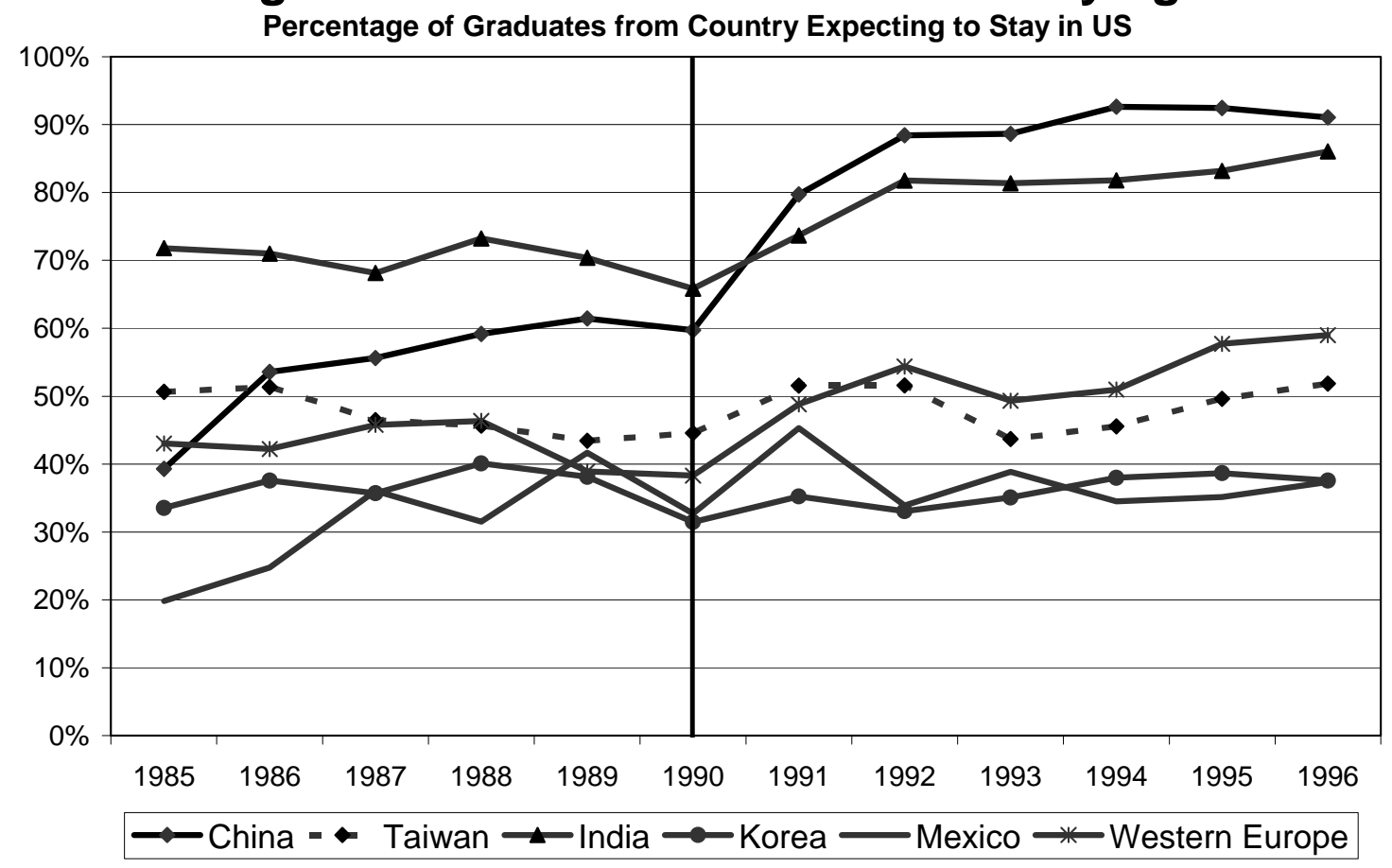

Figure 7: US SE Ph.D. Graduates

Graduates by Country of Origin

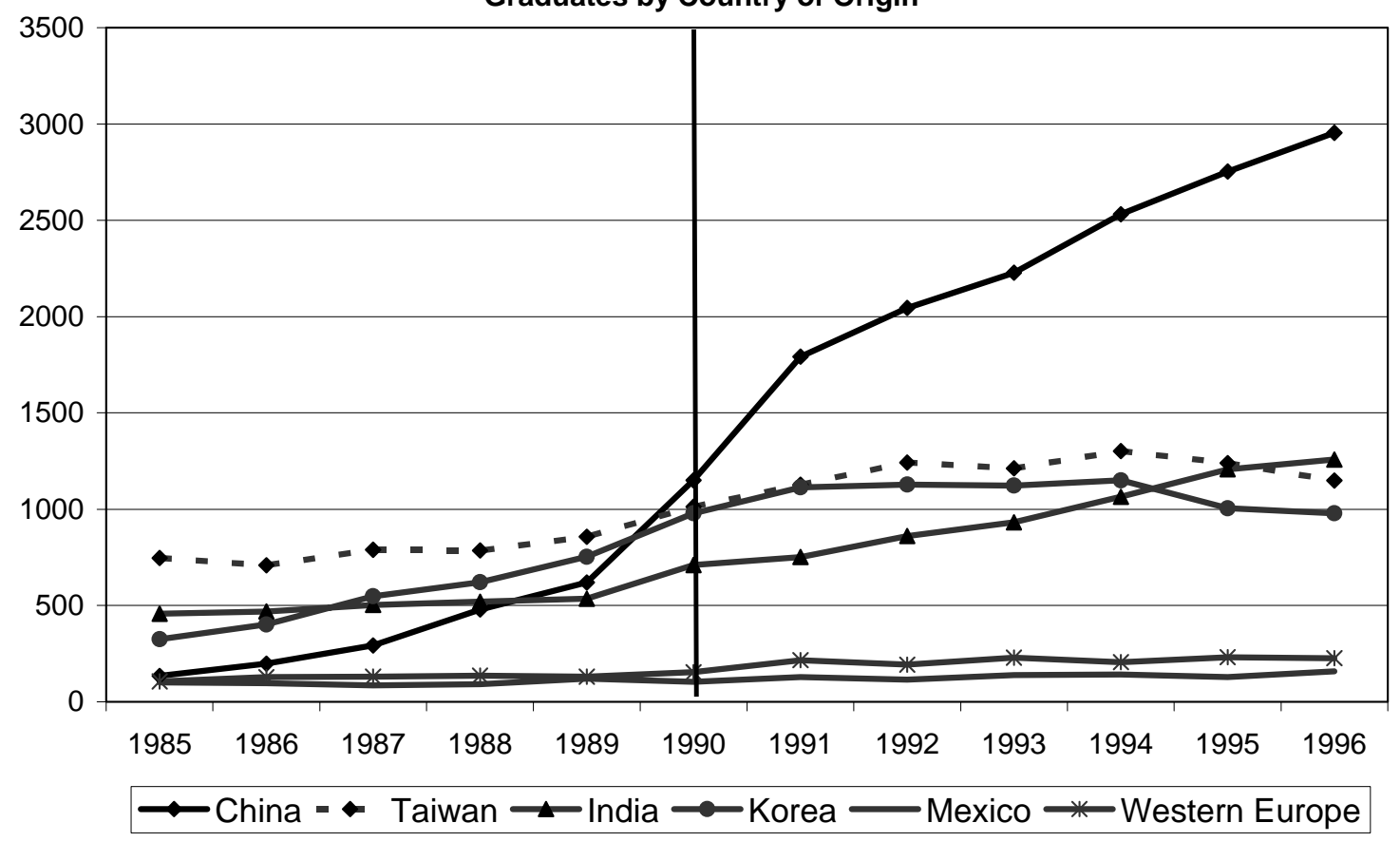


Table 1: Descriptive Statistics for Inventors Residing In US

\begin{tabular}{|c|c|c|c|c|c|c|c|c|c|}
\hline & \multicolumn{9}{|c|}{ Ethnicity of Inventor (Percent Distribution) } \\
\hline & English & Chinese & European & Hispanic & Indian & Japanese & Korean & Russian & Vietnamese \\
\hline & \multicolumn{9}{|c|}{ A. Ethnic Inventor Shares Estimated from US Inventor Records } \\
\hline 1985-1990 Share & 79.7 & 3.7 & 7.3 & 3.3 & 2.9 & 0.8 & 0.7 & 1.5 & 0.2 \\
\hline 1990-1997 Share & 76.4 & 5.4 & 6.9 & 3.7 & 3.7 & 0.9 & 0.8 & 1.7 & 0.4 \\
\hline Chemicals & 74.4 & 6.5 & 7.5 & 3.6 & 4.3 & 0.9 & 0.9 & 1.6 & 0.3 \\
\hline Computers & 75.2 & 6.4 & 6.2 & 3.5 & 4.7 & 0.9 & 0.8 & 1.7 & 0.7 \\
\hline Pharmaceuticals & 75.5 & 5.2 & 7.5 & 4.1 & 3.8 & 1.1 & 1.0 & 1.6 & 0.3 \\
\hline Electrical & 75.0 & 6.3 & 7.0 & 3.6 & 3.7 & 1.0 & 0.9 & 1.9 & 0.5 \\
\hline Mechanical & 81.9 & 2.5 & 7.2 & 3.2 & 2.4 & 0.6 & 0.5 & 1.5 & 0.2 \\
\hline Miscellaneous & 82.6 & 2.4 & 7.0 & 3.5 & 2.0 & 0.5 & 0.5 & 1.3 & 0.2 \\
\hline Top MSAs as a & KC (89) & SF (12) & NYC (11) & MIA (17) & NYC (6) & LA (2) & BAL (3) & BOS (3) & AUS (2) \\
\hline Percentage of MSA's & WS (89) & LA (7) & NOR (11) & $\mathrm{SD}(8)$ & BUF (6) & $\mathrm{SD}(2)$ & COL (2) & NYC (3) & LA (1) \\
\hline \multirow[t]{2}{*}{ Patents } & MEM (86) & NYC (7) & STL (11) & WPB (6) & AUS (6) & SF (2) & $\mathrm{SF}(2)$ & PRO (3) & $\mathrm{SF}(1)$ \\
\hline & \multicolumn{9}{|c|}{ B. Ethnic Scientist and Engineer Shares Estimated from 1990 US Census Records } \\
\hline Bachelors Share & 87.6 & 2.7 & 2.3 & 2.4 & 2.3 & 0.6 & 0.5 & 0.4 & 1.2 \\
\hline Masters Share & 78.9 & 6.7 & 3.4 & 2.2 & 5.4 & 0.9 & 0.7 & 0.8 & 1.0 \\
\hline Doctorate Share & 71.2 & 13.2 & 4.0 & 1.7 & 6.5 & 0.9 & 1.5 & 0.5 & 0.4 \\
\hline
\end{tabular}

Notes: MSAs - AUS (Austin), BAL (Baltimore), BOS (Boston), BUF (Buffalo), COL (Columbus), HRT (Hartford), KC (Kansas City), LA (Los Angeles), MEM (Memphis), MIA (Miami), NOR (New Orleans), NYC (New York City), PRO (Providence), SA (San Antonio), SD (San Diego), SF (San Francisco), STL (St. Louis), WPB (West Palm Beach), and WS (Winston-Salem). MSAs are identified from inventors' city names using city lists collected from the Office of Social and Economic Data Analysis at the University of Missouri, with a matching rate of 98\%. Manual coding further ensures all patents with more than 100 citations and all city names with more than 100 patents are identified. 1990 Census statistics are calculated by country-of-birth using the country-ethnicity groupings listed in Table 4; English provides a residual in the Census statistics. 
Table 2: Descriptive Statistics for Inventors Residing in Foreign Countries and Regions

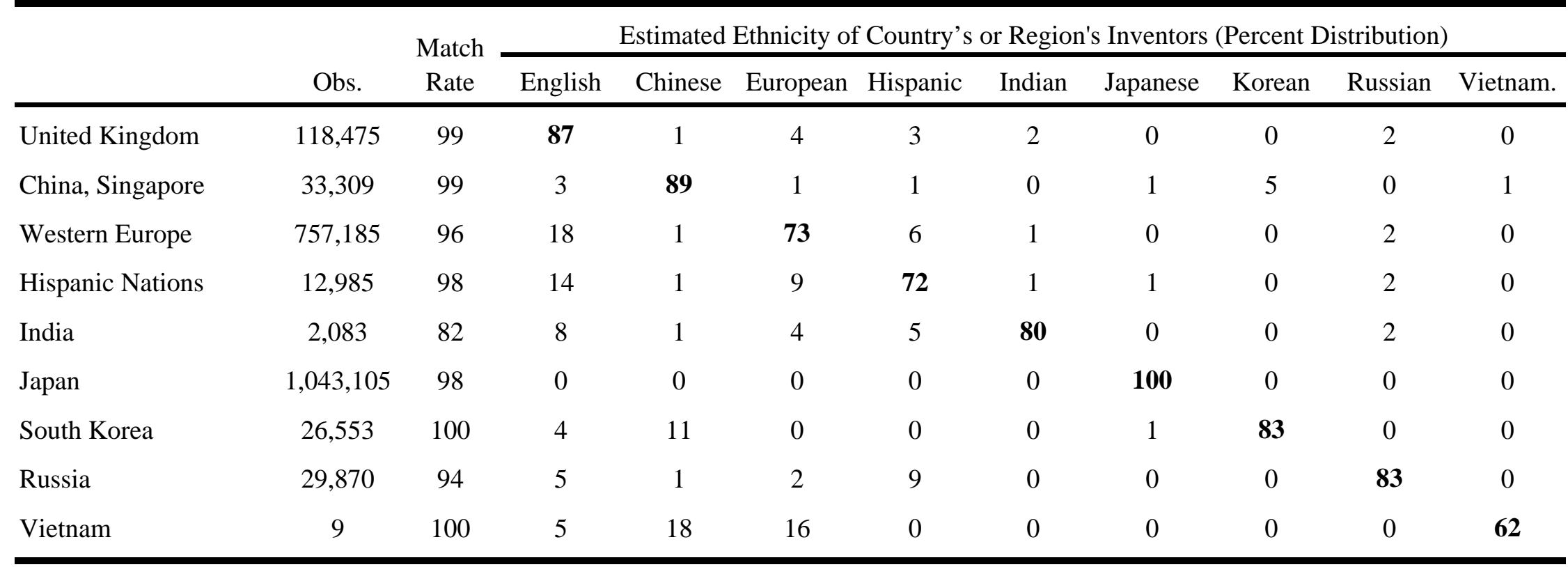

Notes: China includes Mainland China, Hong Kong, Macao, and Taiwan. Western Europe includes Austria, Belgium, Denmark, Finland, France, Germany, Italy, Luxembourg, Netherlands, Norway, Poland, Sweden, and Switzerland. Hispanic Nations includes Argentina, Belize, Brazil, Chile, Columbia, Costa Rica, Cuba, Dominican Republic, Ecuador, El Salvador, Guatemala, Honduras, Mexico, Nicaragua, Panama, Paraguay, Peru, Philippines, Portugal, Spain, Uruguay, and Venezuela. Russia includes former Soviet Union countries.

\section{Table 3: Incidence Rate Ratios for Foreign Patent Citations of US Domestic Patents}

\begin{tabular}{lcccccccccccc}
\hline & \multirow{2}{*}{\begin{tabular}{c} 
All \\
\cline { 3 - 11 }
\end{tabular}} & Citations & 0-2 Yr. & 2-3 Yr. & 3-4 Yr. & 4-5 Yr. & 5-6 Yr. & 6-7 Yr. & 7-8 Yr. & 8-9 Yr. & 9-10 Yr. & $10-11$ Yr. \\
\cline { 3 - 12 } & & 1.496 & 1.315 & 1.402 & 1.485 & 1.524 & 1.332 & 1.399 & 1.348 & 1.320 & 1.332 & 1.159 \\
Incidence Rate Ratio & $(0.052)$ & $(0.089)$ & $(0.085)$ & $(0.085)$ & $(0.088)$ & $(0.079)$ & $(0.087)$ & $(0.086)$ & $(0.088)$ & $(0.092)$ & $(0.084)$ \\
\hline
\end{tabular}

Notes: Negative binomial regressions contain 116,640 cells grouping US international patent citations by the ethnicity of citing foreign inventor, the ethnicity of cited US inventor, the technology class of citing foreign inventor, and the technology class of cited US inventor. Regressions are unweighted and include an indicator variable for same ethnicity, an indicator variable for same technology, and vectors of fixed effects for the four dimensions on which cells are constructed. Coefficients on same-ethnicity indicator variable are transformed into the reported incident rate ratios. 
Table 4: UNIDO Industry Sample

\begin{tabular}{|c|c|c|c|c|c|c|c|c|c|c|}
\hline \multirow[b]{2}{*}{ Country } & \multirow{2}{*}{$\begin{array}{c}1980 \\
\text { Agr. Share }\end{array}$} & \multirow{2}{*}{$\begin{array}{l}\text { UNIDO3 } \\
\text { Panel }\end{array}$} & \multicolumn{2}{|c|}{ Output (m) } & \multicolumn{2}{|c|}{ Labor Prod. (k) } & \multicolumn{2}{|c|}{ Employment (k) } & \multicolumn{2}{|c|}{ Capital (m) } \\
\hline & & & Level & Growth & Level & Growth & Level & Growth & Level & Growth \\
\hline \multicolumn{11}{|c|}{ Single Ethnic Mappings: } \\
\hline India & $70 \%$ & $85-97$ & 117,950 & $6 \%$ & 16 & $3 \%$ & 7,354 & $2 \%$ & 46,740 & $4 \%$ \\
\hline Japan & $11 \%$ & $85-97$ & $2,053,048$ & $7 \%$ & 206 & $8 \%$ & 9,998 & $-1 \%$ & 415,195 & $8 \%$ \\
\hline South Korea & $37 \%$ & $85-97$ & 230,942 & $14 \%$ & 88 & $13 \%$ & 2,626 & $1 \%$ & 88,873 & $14 \%$ \\
\hline Russia & $16 \%$ & $93-97$ & 109,729 & $12 \%$ & 10 & $22 \%$ & 11,685 & $-8 \%$ & & \\
\hline Soviet Union & $16 \%$ & $85-89$ & $1,087,914$ & $7 \%$ & 35 & $8 \%$ & 31,434 & $-1 \%$ & & \\
\hline \multicolumn{11}{|c|}{ Chinese Economies: } \\
\hline China, Mainland & $74 \%$ & $85-97$ & 327,173 & $11 \%$ & 8 & $9 \%$ & 38,940 & $3 \%$ & & \\
\hline Hong Kong & $1 \%$ & $85-97$ & 30,520 & $3 \%$ & 66 & $12 \%$ & 535 & $-9 \%$ & 6,628 & $3 \%$ \\
\hline Масао & $6 \%$ & $85-97$ & 1,209 & $8 \%$ & 26 & $10 \%$ & 49 & $-2 \%$ & 235 & $1 \%$ \\
\hline Singapore & $2 \%$ & $85-97$ & 37,830 & $16 \%$ & 117 & $12 \%$ & 309 & $3 \%$ & 8,477 & $8 \%$ \\
\hline Taiwan & $8 \%$ & $85-96$ & 145,055 & $11 \%$ & 68 & $11 \%$ & 2,141 & $0 \%$ & & \\
\hline \multicolumn{11}{|c|}{ European Economies: } \\
\hline Austria & $10 \%$ & $85-97$ & 73,524 & $5 \%$ & 125 & $5 \%$ & 595 & $0 \%$ & 22,001 & $5 \%$ \\
\hline Belgium & $3 \%$ & 85-92, 95-97 & 31,958 & $5 \%$ & 131 & $7 \%$ & 247 & $-2 \%$ & 19,809 & $7 \%$ \\
\hline Denmark & $7 \%$ & $85-91$ & 38,198 & $9 \%$ & 93 & $11 \%$ & 411 & $-1 \%$ & 8,788 & $7 \%$ \\
\hline Finland & $12 \%$ & $85-97$ & 52,510 & $4 \%$ & 141 & $8 \%$ & 386 & $-4 \%$ & 18,868 & $1 \%$ \\
\hline France & $8 \%$ & $85-96$ & 517,276 & $8 \%$ & 130 & $10 \%$ & 4,006 & $-2 \%$ & 107,758 & $4 \%$ \\
\hline Germany & $7 \%$ & $91-97$ & 870,625 & $7 \%$ & 147 & $7 \%$ & 5,920 & $0 \%$ & & \\
\hline Germany, East & & $85-92$ & 233,905 & $12 \%$ & 81 & $12 \%$ & 2,902 & $0 \%$ & & \\
\hline Germany, West & & $85-89$ & 734,523 & $12 \%$ & 115 & $12 \%$ & 6,391 & $0 \%$ & 51,571 & $-6 \%$ \\
\hline Italy & $13 \%$ & 85-94, 96-97 & 390,266 & $7 \%$ & 134 & $7 \%$ & 2,897 & $0 \%$ & 79,391 & $6 \%$ \\
\hline Luxembourg & $5 \%$ & $85-97$ & 2,952 & $3 \%$ & 137 & $5 \%$ & 22 & $-1 \%$ & 730 & $1 \%$ \\
\hline Netherlands & $6 \%$ & $85-97$ & 117,868 & $6 \%$ & 178 & $7 \%$ & 670 & $-1 \%$ & 29,146 & $6 \%$ \\
\hline Norway & $8 \%$ & $85-97$ & 37,467 & $4 \%$ & 149 & $6 \%$ & 256 & $-2 \%$ & 10,402 & $-1 \%$ \\
\hline Poland & $30 \%$ & $90-97$ & 54,895 & $6 \%$ & 21 & $7 \%$ & 2,650 & $-1 \%$ & 18,749 & $1 \%$ \\
\hline Sweden & $6 \%$ & $85-97$ & 93,727 & $6 \%$ & 140 & $7 \%$ & 678 & $-1 \%$ & 23,192 & $4 \%$ \\
\hline Switzerland & $6 \%$ & $86-96$ & 37,827 & $7 \%$ & 142 & $8 \%$ & 270 & $-2 \%$ & & \\
\hline
\end{tabular}


Table 4: UNIDO Industry Sample (continued)

\begin{tabular}{lccccccccc}
\hline & 1980 & UNIDO3 & \multicolumn{2}{c}{ Output (m) } & \multicolumn{2}{c}{ Labor Prod. (k) } & \multicolumn{2}{c}{ Employment (k) } & \multicolumn{2}{c}{ Capital (m) } \\
Country & Agr. Share & Panel & Level & Growth & Level & Growth & Level & Growth & Level \\
Growth
\end{tabular}

Notes: Values are in 1987 US dollars. Levels and growth rates are unweighted averages of yearly country-level aggregates derived from the industry data used in the UNIDO3 panel. Belize, Dominican Republic, El Salvador, Guatemala, Latvia, Lithuania, Nicaragua, Paraguay, and Vietnam are not included due to lack of data. For countries in the sample, insufficient observations or severe quality concerns excluded observations in Bolivia (353 in 1985, 355 and 382 in 1987), Brazil (1985), Costa Rica (371, 385 in 1997), Ecuador (352 in 1994, 354 in 1995, 313 in 1997), Honduras (1981-1989), Hong Kong (369 in 1996), Macao (314) and Venezuela (314 in 1996, 371 in 1995). Series breaks are modeled for Argentina (1990), Austria (1985), China (1989), Denmark (1989), Italy (1994), Mexico (1993), and Portugal (1989) for distinct levels shifts over the 1985-1997 period usually due to changes in variable definitions.

ISIC Rev. 2 Industries: Food products (311), Beverages (313), Tobacco (314), Textiles (321), Wearing apparel, except footwear (322), Leather products (323), Footwear, except rubber or plastic (324), Wood products, except furniture (331), Furniture, except metal (332), Paper and products (341), Printing and publishing (342), Industrial chemicals (351), Other chemicals (352), Petroleum refineries (353), Misc. petroleum and coal products (354), Rubber products (355), Plastic products (356), Pottery, china, earthenware (361), Glass and products (362), Other non-metallic mineral products (369), Iron and steel (371), Non-ferrous metals (372), Fabricated metal products (381), Machinery, except electrical (382), Machinery, electric (383), Transport equipment (384), Professional \& scientific equipment (385), and Other manufactured products (390). Industry 390 is excluded. 
Table 5A: UNIDO Levels Specification

\begin{tabular}{ccc}
$\begin{array}{c}\text { No } \\
\text { Weights }\end{array}$ & $\begin{array}{c}\text { Patent } \\
\text { Weights }\end{array}$ & $\begin{array}{c}\text { Output } \\
\text { Weights }\end{array}$ \\
\hline$(1)$ & $(2)$ & $(3)$ \\
\hline
\end{tabular}

A. Log Foreign Output

Log US Ethnic

Research Community

0.241

0.420

(0.242)

0.400

(0.134)

9912

$(0.156)$

Observations

9912

9912

B. Log Foreign Labor Productivity

\begin{abstract}
Log US Ethnic
Research Community
\end{abstract}

0.215
$(0.094)$

0.383

$(0.191)$

0.310

9912

9912

(0.132)

Observations

9912

C. Log Foreign Employment

\begin{tabular}{lccc} 
Log US Ethnic & 0.026 & 0.037 & 0.090 \\
Research Community & $(0.146)$ & $(0.212)$ & $(0.148)$ \\
Observations & 9912 & 9912 & 9912 \\
\hline Notes: Row titles document the dependent variable studied; column titles
\end{tabular}

Notes: Row titles document the dependent variable studied; column titles

document the weighting scheme employed. Panel estimations consider countryindustry observations taken from the 1985-1997 UNIDO manufacturing database. Log US Ethnic Research Communities are estimated at the ethnicity-industry level from the US ethnic patenting dataset. Regressions include industry-year and country-industry fixed effects. Standard errors are clustered at the ethnicityindustry level.

Table 5B: UNIDO First-Differences Specification

\begin{tabular}{ccc}
$\begin{array}{c}\text { No } \\
\text { Weights }\end{array}$ & $\begin{array}{c}\text { Patent } \\
\text { Weights }\end{array}$ & $\begin{array}{c}\text { Output } \\
\text { Weights }\end{array}$ \\
\hline$(1)$ & $(2)$ & $(3)$ \\
\hline
\end{tabular}

A. $\Delta$ Log Foreign Output

$\Delta$ Log US Ethnic

$\begin{array}{ccc}0.091 & 0.340 & 0.285 \\ (0.057) & (0.135) & (0.075) \\ 8736 & 8736 & 8736\end{array}$

Observations

B. $\Delta$ Log Foreign Labor Productivity

\section{$\Delta$ Log US Ethnic \\ Research Community}

Observations

\begin{abstract}
$\Delta$ Log US Ethnic
Research Community
\end{abstract}

Observations

$\begin{array}{ccc}0.087 & 0.214 & 0.217 \\ (0.050) & (0.116) & (0.073) \\ 8736 & 8736 & 8736\end{array}$

C. $\Delta$ Log Foreign Employment

$\begin{array}{ccc}0.003 & 0.127 & 0.068 \\ (0.037) & (0.085) & (0.048) \\ 8736 & 8736 & 8736\end{array}$

Notes: Row titles document the dependent variable studied; column titles document the weighting scheme employed. Panel estimations consider countryindustry observations taken from the 1985-1997 UNIDO manufacturing database. Log US Ethnic Research Communities are estimated at the ethnicity-industry level from the US ethnic patenting dataset. Regressions include industry-year fixed effects. Standard errors are clustered at the ethnicity-industry level. 
Table 6A: UNIDO Country Controls - Levels

\begin{tabular}{|c|c|c|c|}
\hline & $\begin{array}{c}\text { No } \\
\text { Weights }\end{array}$ & $\begin{array}{c}\text { Patent } \\
\text { Weights }\end{array}$ & $\begin{array}{l}\text { Output } \\
\text { Weights }\end{array}$ \\
\hline & $(1)$ & (2) & (3) \\
\hline & \multicolumn{3}{|c|}{ A. Base Foreign Output Regression } \\
\hline $\begin{array}{l}\text { Log US Ethnic } \\
\text { Research Community }\end{array}$ & $\begin{array}{c}0.241 \\
(0.134)\end{array}$ & $\begin{array}{c}0.420 \\
(0.242)\end{array}$ & $\begin{array}{c}0.400 \\
(0.156)\end{array}$ \\
\hline \multirow[t]{2}{*}{ Observations } & 9912 & 9912 & 9912 \\
\hline & \multicolumn{3}{|c|}{ B. Including Foreign Ph.D. Students in US } \\
\hline $\begin{array}{l}\text { Log US Ethnic } \\
\text { Research Community }\end{array}$ & $\begin{array}{c}0.225 \\
(0.268)\end{array}$ & $\begin{array}{c}0.294 \\
(0.229)\end{array}$ & $\begin{array}{c}0.337 \\
(0.265)\end{array}$ \\
\hline $\begin{array}{l}\text { Log Foreign Ph.D. } \\
\text { Students in US }\end{array}$ & $\begin{array}{c}0.016 \\
(0.093)\end{array}$ & $\begin{array}{c}0.100 \\
(0.089)\end{array}$ & $\begin{array}{c}0.054 \\
(0.097)\end{array}$ \\
\hline \multirow[t]{2}{*}{ Observations } & 8914 & 8914 & 8914 \\
\hline & \multicolumn{3}{|c|}{ C. Including Country Time Trends } \\
\hline $\begin{array}{l}\text { Log US Ethnic } \\
\text { Research Community }\end{array}$ & $\begin{array}{c}0.024 \\
(0.120)\end{array}$ & $\begin{array}{c}0.078 \\
(0.205)\end{array}$ & $\begin{array}{c}0.090 \\
(0.137)\end{array}$ \\
\hline \multirow{2}{*}{ Observations } & 9912 & 9912 & 9912 \\
\hline & \multicolumn{3}{|c|}{ D. Including Country-Year Effects } \\
\hline $\begin{array}{l}\text { Log US Ethnic } \\
\text { Research Community }\end{array}$ & $\begin{array}{c}0.021 \\
(0.119)\end{array}$ & $\begin{array}{c}0.243 \\
(0.292)\end{array}$ & $\begin{array}{c}0.094 \\
(0.164)\end{array}$ \\
\hline Observations & 9912 & 9912 & 9912 \\
\hline
\end{tabular}

Notes: See Table 5A. Panel A replicates the foreign country-industry output regressions (levels) from Table 5A. Panels B through D incorporate the countryyear controls indicated by the row titles. Regressions also maintain industry-year and country-industry fixed effects.

Table 6B: UNIDO Country Controls - First-Differences

\begin{tabular}{lccc}
\hline & $\begin{array}{c}\text { No } \\
\text { Weights }\end{array}$ & $\begin{array}{c}\text { Patent } \\
\text { Weights }\end{array}$ & $\begin{array}{c}\text { Output } \\
\text { Weights }\end{array}$ \\
\cline { 2 - 4 } & $(1)$ & $(2)$ & $(3)$ \\
\hline & \multicolumn{2}{c}{ A. Base Foreign Output Regression } \\
$\Delta$ Log US Ethnic & 0.091 & 0.340 & 0.285 \\
Research Community & $(0.057)$ & $(0.135)$ & $(0.075)$ \\
Observations & 8736 & 8736 & 8736
\end{tabular}

B. Including Foreign Ph.D. Students in US

\section{$\Delta$ Log US Ethnic \\ Research Community \\ $\Delta$ Log Foreign Ph.D. \\ Students in US \\ Observations}

\section{$\Delta$ Log US Ethnic \\ Research Community}

Observations

\begin{abstract}
$\Delta$ Log US Ethnic
Research Community
\end{abstract}

Observations

$\begin{array}{ccc}0.061 & 0.313 & 0.210 \\ (0.035) & (0.075) & (0.066) \\ 0.038 & 0.050 & 0.053 \\ (0.070) & (0.082) & (0.074) \\ 7780 & 7780 & 7780\end{array}$

C. Including Country Time Trends

$\begin{array}{ccc}0.000 & 0.130 & 0.153 \\ (0.062) & (0.104) & (0.069) \\ 8736 & 8736 & 8736\end{array}$

D. Including Country-Year Effects

$\begin{array}{ccc}-0.092 & 0.149 & -0.022 \\ (0.049) & (0.109) & (0.060)\end{array}$

Notes: See Table 5B. Panel A replicates the foreign country-industry output regressions (first-differences) from Table 5B. Panels B through D incorporate the country-year controls indicated by the row titles. Regressions also maintain industry-year fixed effects. 
Table 7A: UNIDO Capital-Labor - Levels

\begin{tabular}{ccc}
$\begin{array}{c}\text { No } \\
\text { Weights }\end{array}$ & $\begin{array}{c}\text { Patent } \\
\text { Weights }\end{array}$ & $\begin{array}{c}\text { Output } \\
\text { Weights }\end{array}$ \\
\hline$(1)$ & $(2)$ & $(3)$ \\
\hline
\end{tabular}

A. Base Foreign Productivity Regression

\begin{tabular}{lccc} 
Log US Ethnic & 0.215 & 0.383 & 0.310 \\
Research Community & $(0.094)$ & $(0.191)$ & $(0.132)$ \\
Observations & 9912 & 9912 & 9912 \\
& \multicolumn{2}{c}{ B. Restricted Capital Sample } \\
Log US Ethnic & 0.132 & 0.445 & 0.295 \\
Research Community & $(0.140)$ & $(0.267)$ & $(0.184)$ \\
Observations & 5604 & 5604 & 5604 \\
& C. Including Capital-Labor Ratio \\
Log US Ethnic & 0.121 & 0.332 & 0.238 \\
Research Community & $(0.128)$ & $(0.257)$ & $(0.170)$ \\
Log Foreign & 0.212 & 0.244 & 0.216 \\
Capital-Labor Ratio & $(0.065)$ & $(0.054)$ & $(0.059)$ \\
Observations & 5604 & 5604 & 5604 \\
\hline
\end{tabular}

Notes: See Table 5A. Panel A replicates the foreign country-industry labor productivity regressions (levels) from Table 5A. Panel B re-estimates the labor productivity regressions for observations with capital data. Panel $\mathrm{C}$ incorporates the foreign country-industry capital-labor ratios. Regressions also maintain industry-year and country-industry fixed effects.

Table 7B: UNIDO Capital-Labor - First-Differences

\begin{tabular}{ccc}
$\begin{array}{c}\text { No } \\
\text { Weights }\end{array}$ & $\begin{array}{c}\text { Patent } \\
\text { Weights }\end{array}$ & $\begin{array}{c}\text { Output } \\
\text { Weights }\end{array}$ \\
\hline$(1)$ & $(2)$ & $(3)$ \\
\hline
\end{tabular}

A. Base Foreign Productivity Regression

\section{$\Delta$ Log US Ethnic \\ Research Community}

Observations

$\Delta$ Log US Ethnic
Research Community
Observations

$\Delta$ Log US Ethnic
Research Community
$\Delta$ Log Foreign
Capital-Labor Ratio
Observations

$\Delta$ Log US Ethnic

ations
Observations

$\begin{array}{ccc}0.087 & 0.214 & 0.217 \\ (0.050) & (0.116) & (0.073) \\ 8736 & 8736 & 8736\end{array}$

B. Restricted Capital Sample

$\begin{array}{ccc}0.044 & 0.194 & 0.166 \\ (0.064) & (0.148) & (0.089) \\ 4866 & 4866 & 4866\end{array}$

C. Including Capital-Labor Ratio

$\begin{array}{ccc}0.049 & 0.191 & 0.164 \\ (0.062) & (0.148) & (0.087) \\ 0.111 & 0.033 & 0.083 \\ (0.029) & (0.043) & (0.035) \\ 4866 & 4866 & 4866\end{array}$

Notes: See Table 5B. Panel A replicates the foreign country-industry labor productivity regressions (first-differences) from Table 5B. Panel B re-estimates the labor productivity regressions for observations with capital data. Panel C incorporates the foreign country-industry capital-labor ratios. Regressions also maintain industry-year fixed effects. 
Table 8A: UNIDO Sector Reallocation Regressions - Levels

\begin{tabular}{|c|c|c|c|c|c|c|c|c|}
\hline & & & & \multicolumn{5}{|c|}{ Patent Weights } \\
\hline & $\begin{array}{c}\text { No } \\
\text { Weights }\end{array}$ & $\begin{array}{l}\text { Patent } \\
\text { Weights }\end{array}$ & $\begin{array}{l}\text { Output } \\
\text { Weights }\end{array}$ & $\begin{array}{l}\text { Excluding } \\
\text { Computers } \\
\text { and Drugs }\end{array}$ & $\begin{array}{c}\text { Excluding } \\
\text { Mainland } \\
\text { China }\end{array}$ & $\begin{array}{c}\text { Excluding } \\
\text { All Chinese } \\
\text { Economies }\end{array}$ & $\begin{array}{c}\text { Excluding } \\
\text { All Advanced } \\
\text { Economies }\end{array}$ & $\begin{array}{c}\text { Excluding } \\
\text { All Hispanic } \\
\text { Economies }\end{array}$ \\
\hline & $(1)$ & $(2)$ & (3) & (4) & (5) & $(6)$ & $(7)$ & $(8)$ \\
\hline & \multicolumn{8}{|c|}{ A. Log Foreign Output } \\
\hline $\begin{array}{l}\text { Log US Ethnic } \\
\text { Research Community }\end{array}$ & $\begin{array}{c}0.237 \\
(0.136)\end{array}$ & $\begin{array}{c}0.431 \\
(0.248)\end{array}$ & $\begin{array}{c}0.414 \\
(0.164)\end{array}$ & $\begin{array}{c}0.105 \\
(0.163)\end{array}$ & $\begin{array}{c}0.431 \\
(0.279)\end{array}$ & $\begin{array}{c}0.034 \\
(0.391)\end{array}$ & $\begin{array}{c}0.512 \\
(0.263)\end{array}$ & $\begin{array}{c}0.463 \\
(0.278)\end{array}$ \\
\hline $\begin{array}{l}\text { Log US Ethnic Comm. } \\
\text { x } 1980 \text { Agriculture Share }\end{array}$ & $\begin{array}{c}0.667 \\
(0.252)\end{array}$ & $\begin{array}{c}0.340 \\
(0.419)\end{array}$ & $\begin{array}{c}0.606 \\
(0.312)\end{array}$ & $\begin{array}{c}0.653 \\
(0.279)\end{array}$ & $\begin{array}{c}0.343 \\
(0.440)\end{array}$ & $\begin{array}{c}0.810 \\
(0.605)\end{array}$ & $\begin{array}{c}0.307 \\
(0.466)\end{array}$ & $\begin{array}{c}0.076 \\
(0.429)\end{array}$ \\
\hline \multirow[t]{2}{*}{ Observations } & 9912 & 9912 & 9912 & 9067 & 9653 & 8669 & 6259 & 5453 \\
\hline & \multicolumn{8}{|c|}{ B. Log Foreign Labor Productivity } \\
\hline $\begin{array}{l}\text { Log US Ethnic } \\
\text { Research Community }\end{array}$ & $\begin{array}{c}0.220 \\
(0.069)\end{array}$ & $\begin{array}{c}0.360 \\
(0.142)\end{array}$ & $\begin{array}{c}0.294 \\
(0.099)\end{array}$ & $\begin{array}{c}0.261 \\
(0.175)\end{array}$ & $\begin{array}{c}0.294 \\
(0.130)\end{array}$ & $\begin{array}{l}-0.153 \\
(0.306)\end{array}$ & $\begin{array}{c}0.772 \\
(0.159)\end{array}$ & $\begin{array}{c}0.399 \\
(0.096)\end{array}$ \\
\hline $\begin{array}{l}\text { Log US Ethnic Comm. } \\
\text { x } 1980 \text { Agriculture Share }\end{array}$ & $\begin{array}{l}-0.855 \\
(0.108)\end{array}$ & $\begin{array}{l}-0.665 \\
(0.182)\end{array}$ & $\begin{array}{l}-0.654 \\
(0.138)\end{array}$ & $\begin{array}{l}-0.707 \\
(0.214)\end{array}$ & $\begin{array}{l}-0.876 \\
(0.199)\end{array}$ & $\begin{array}{l}-0.362 \\
(0.298)\end{array}$ & $\begin{array}{l}-0.512 \\
(0.223)\end{array}$ & $\begin{array}{l}-0.510 \\
(0.262)\end{array}$ \\
\hline \multirow[t]{2}{*}{ Observations } & 9912 & 9912 & 9912 & 9067 & 9653 & 8669 & 6259 & 5453 \\
\hline & \multicolumn{8}{|c|}{ C. Log Foreign Employment } \\
\hline $\begin{array}{l}\text { Log US Ethnic } \\
\text { Research Community }\end{array}$ & $\begin{array}{c}0.017 \\
(0.122)\end{array}$ & $\begin{array}{c}0.072 \\
(0.177)\end{array}$ & $\begin{array}{c}0.120 \\
(0.114)\end{array}$ & $\begin{array}{l}-0.155 \\
(0.100)\end{array}$ & $\begin{array}{c}0.138 \\
(0.200)\end{array}$ & $\begin{array}{c}0.187 \\
(0.198)\end{array}$ & $\begin{array}{l}-0.260 \\
(0.172)\end{array}$ & $\begin{array}{c}0.063 \\
(0.197)\end{array}$ \\
\hline $\begin{array}{l}\text { Log US Ethnic Comm. } \\
\text { x } 1980 \text { Agriculture Share }\end{array}$ & $\begin{array}{c}1.521 \\
(0.220)\end{array}$ & $\begin{array}{c}1.005 \\
(0.336)\end{array}$ & $\begin{array}{c}1.260 \\
(0.252)\end{array}$ & $\begin{array}{c}1.360 \\
(0.273)\end{array}$ & $\begin{array}{l}1.220 \\
(0.334)\end{array}$ & $\begin{array}{l}1.172 \\
(0.416)\end{array}$ & $\begin{array}{c}0.818 \\
(0.340)\end{array}$ & $\begin{array}{c}0.586 \\
(0.286)\end{array}$ \\
\hline Observations & 9912 & 9912 & 9912 & 9067 & 9653 & 8669 & 6259 & 5453 \\
\hline
\end{tabular}

Notes: Row titles document the dependent variable studied; column titles document the weighting scheme employed. Panel estimations consider country-industry observations taken from the 1985-1997 UNIDO manufacturing database. 1980 Agriculture Shares for foreign countries are listed in Table 4. Log US Ethnic Research Communities are estimated at the ethnicity-industry level from the US ethnic patenting dataset. Main effects are demeaned prior to interaction. Regressions include industry-year and country-industry fixed effects. Standard errors are clustered at the ethnicity-industry level. 
Table 8B: UNIDO Sector Reallocation Regressions - First-Differences

\begin{tabular}{|c|c|c|c|c|c|c|c|c|}
\hline & & & & \multicolumn{5}{|c|}{ Patent Weights } \\
\hline & $\begin{array}{c}\text { No } \\
\text { Weights }\end{array}$ & $\begin{array}{l}\text { Patent } \\
\text { Weights }\end{array}$ & $\begin{array}{l}\text { Output } \\
\text { Weights }\end{array}$ & $\begin{array}{c}\text { Excluding } \\
\text { Computers } \\
\text { and Drugs }\end{array}$ & $\begin{array}{c}\text { Excluding } \\
\text { Mainland } \\
\text { China }\end{array}$ & $\begin{array}{c}\text { Excluding } \\
\text { All Chinese } \\
\text { Economies }\end{array}$ & $\begin{array}{c}\text { Excluding } \\
\text { All Advanced } \\
\text { Economies }\end{array}$ & $\begin{array}{l}\text { Excluding } \\
\text { All Hispanic } \\
\text { Economies }\end{array}$ \\
\hline & $(1)$ & $(2)$ & (3) & (4) & (5) & $(6)$ & $(7)$ & $(8)$ \\
\hline & \multicolumn{8}{|c|}{ A. $\Delta$ Log Foreign Output } \\
\hline $\begin{array}{l}\Delta \text { Log US Ethnic } \\
\text { Research Community }\end{array}$ & $\begin{array}{c}0.043 \\
(0.063)\end{array}$ & $\begin{array}{c}0.315 \\
(0.155)\end{array}$ & $\begin{array}{c}0.252 \\
(0.087)\end{array}$ & $\begin{array}{c}0.083 \\
(0.094)\end{array}$ & $\begin{array}{c}0.315 \\
(0.179)\end{array}$ & $\begin{array}{c}0.019 \\
(0.132)\end{array}$ & $\begin{array}{c}0.425 \\
(0.129)\end{array}$ & $\begin{array}{c}0.295 \\
(0.209)\end{array}$ \\
\hline $\begin{array}{l}\Delta \text { Log US Ethnic Comm. } \\
\text { x } 1980 \text { Agriculture Share }\end{array}$ & $\begin{array}{c}0.765 \\
(0.188)\end{array}$ & $\begin{array}{c}0.442 \\
(0.359)\end{array}$ & $\begin{array}{c}0.647 \\
(0.247)\end{array}$ & $\begin{array}{c}0.754 \\
(0.193)\end{array}$ & $\begin{array}{c}0.322 \\
(0.357)\end{array}$ & $\begin{array}{c}0.793 \\
(0.386)\end{array}$ & $\begin{array}{c}0.349 \\
(0.377)\end{array}$ & $\begin{array}{c}0.283 \\
(0.388)\end{array}$ \\
\hline \multirow[t]{2}{*}{ Observations } & 8736 & 8736 & 8736 & 7991 & 8518 & 7616 & 5549 & 4821 \\
\hline & \multicolumn{8}{|c|}{ B. $\Delta$ Log Foreign Labor Productivity } \\
\hline $\begin{array}{l}\Delta \text { Log US Ethnic } \\
\text { Research Community }\end{array}$ & $\begin{array}{c}0.105 \\
(0.048)\end{array}$ & $\begin{array}{c}0.225 \\
(0.108)\end{array}$ & $\begin{array}{c}0.228 \\
(0.069)\end{array}$ & $\begin{array}{c}0.109 \\
(0.106)\end{array}$ & $\begin{array}{c}0.173 \\
(0.097)\end{array}$ & $\begin{array}{l}-0.083 \\
(0.119)\end{array}$ & $\begin{array}{c}0.498 \\
(0.102)\end{array}$ & $\begin{array}{c}0.219 \\
(0.099)\end{array}$ \\
\hline $\begin{array}{l}\Delta \text { Log US Ethnic Comm. } \\
\text { x } 1980 \text { Agriculture Share }\end{array}$ & $\begin{array}{l}-0.284 \\
(0.099)\end{array}$ & $\begin{array}{l}-0.191 \\
(0.165)\end{array}$ & $\begin{array}{l}-0.216 \\
(0.122)\end{array}$ & $\begin{array}{l}-0.167 \\
(0.202)\end{array}$ & $\begin{array}{l}-0.572 \\
(0.161)\end{array}$ & $\begin{array}{l}-0.169 \\
(0.192)\end{array}$ & $\begin{array}{l}-0.237 \\
(0.169)\end{array}$ & $\begin{array}{l}-0.053 \\
(0.217)\end{array}$ \\
\hline \multirow[t]{2}{*}{ Observations } & 8736 & 8736 & 8736 & 7991 & 8518 & 7616 & 5549 & 4821 \\
\hline & \multicolumn{8}{|c|}{ C. $\Delta$ Log Foreign Employment } \\
\hline $\begin{array}{l}\Delta \text { Log US Ethnic } \\
\text { Research Community }\end{array}$ & $\begin{array}{l}-0.062 \\
(0.038)\end{array}$ & $\begin{array}{c}0.091 \\
(0.085)\end{array}$ & $\begin{array}{c}0.024 \\
(0.048)\end{array}$ & $\begin{array}{l}-0.026 \\
(0.049)\end{array}$ & $\begin{array}{c}0.142 \\
(0.105)\end{array}$ & $\begin{array}{c}0.102 \\
(0.096)\end{array}$ & $\begin{array}{l}-0.073 \\
(0.063)\end{array}$ & $\begin{array}{c}0.076 \\
(0.121)\end{array}$ \\
\hline $\begin{array}{l}\Delta \text { Log US Ethnic Comm. } \\
\text { x } 1980 \text { Agriculture Share }\end{array}$ & $\begin{array}{c}1.049 \\
(0.149)\end{array}$ & $\begin{array}{c}0.633 \\
(0.271)\end{array}$ & $\begin{array}{c}0.863 \\
(0.202)\end{array}$ & $\begin{array}{c}0.922 \\
(0.190)\end{array}$ & $\begin{array}{c}0.894 \\
(0.264)\end{array}$ & $\begin{array}{c}0.962 \\
(0.308)\end{array}$ & $\begin{array}{c}0.586 \\
(0.290)\end{array}$ & $\begin{array}{c}0.336 \\
(0.241)\end{array}$ \\
\hline Observations & 8736 & 8736 & 8736 & 7991 & 8518 & 7616 & 5549 & 4821 \\
\hline
\end{tabular}

Notes: Row titles document the dependent variable studied; column titles document the weighting scheme employed. Panel estimations consider country-industry observations taken from the 1985-1997 UNIDO manufacturing database. 1980 Agriculture Shares for foreign countries are listed in Table 4. Log US Ethnic Research Communities are estimated at the ethnicity-industry level from the US ethnic patenting dataset. Main effects are demeaned prior to interactions. Regressions include industry-year fixed effects. Standard errors are clustered at the ethnicity-industry level. 


\begin{tabular}{|c|c|c|c|c|c|c|c|}
\hline & \multirow{2}{*}{\multicolumn{3}{|c|}{$\begin{array}{c}\text { Regressions of Immigration Response to } \\
1990 \text { Act (Thousands) } \\
\text { By Occupation }\end{array}$}} & & \multicolumn{3}{|c|}{$\begin{array}{l}\text { Regressions of Log US Ethnic Patents on } \\
\text { Log US Immigration Quotas }\end{array}$} \\
\hline & & & & & \multirow{2}{*}{$\begin{array}{c}\text { No } \\
\text { Weights }\end{array}$} & \multirow{2}{*}{$\begin{array}{l}\text { Patent } \\
\text { Weights }\end{array}$} & \multirow{2}{*}{$\begin{array}{c}\text { Output } \\
\text { Weights }\end{array}$} \\
\hline & Scientists & Business & Total & & & & \\
\hline $\begin{array}{l}\text { 1983-1990 Quota } \\
\text { Share x Post } 1990\end{array}$ & $\begin{array}{c}4.669 \\
(0.183)\end{array}$ & $\begin{array}{c}4.842 \\
(0.127)\end{array}$ & $\begin{array}{c}3.279 \\
(0.125)\end{array}$ & $\begin{array}{l}\text { Log US Immigration } \\
\text { Quotas Estimator }\end{array}$ & $\begin{array}{c}0.217 \\
(0.102)\end{array}$ & $\begin{array}{c}0.256 \\
(0.127)\end{array}$ & $\begin{array}{c}0.213 \\
(0.104)\end{array}$ \\
\hline \multirow[t]{3}{*}{ Observations } & 2310 & 2310 & 2310 & Observations & 9912 & 9912 & 9912 \\
\hline & \multicolumn{3}{|c|}{$\begin{array}{l}\text { 1983-1990 Percent of Theoretical } \\
\text { Employment Quota for Country }\end{array}$} & & \multicolumn{3}{|c|}{$\begin{array}{c}\text { Employment Visa Waiting List } \\
\text { January } 1992\end{array}$} \\
\hline & Scientists & Business & Total & & High-Skill & Skilled & Low-Skill \\
\hline Hong Kong & $20.5 \%$ & $15.6 \%$ & $102.6 \%$ & The Philippines & 6795 & 9550 & 5995 \\
\hline India & $18.5 \%$ & $5.7 \%$ & 83.3\% & Mainland China & 3266 & 1942 & 2976 \\
\hline Taiwan & $18.2 \%$ & $10.8 \%$ & $102.0 \%$ & India & 3132 & 1156 & 1131 \\
\hline United Kingdom & $11.7 \%$ & $13.9 \%$ & $103.7 \%$ & Taiwan & 2065 & 2411 & 1613 \\
\hline Iran & $8.4 \%$ & $4.5 \%$ & $54.1 \%$ & Nigeria & 1854 & 166 & 298 \\
\hline Mainland China & $6.5 \%$ & $5.3 \%$ & $57.1 \%$ & Great Britain & 1841 & 2521 & 714 \\
\hline The Philippines & $4.6 \%$ & $8.4 \%$ & $96.4 \%$ & Canada & 1587 & 2107 & 191 \\
\hline Canada & $3.8 \%$ & $9.5 \%$ & $67.7 \%$ & Hong Kong & 811 & 1350 & 885 \\
\hline South Korea & $2.2 \%$ & $5.0 \%$ & $69.0 \%$ & Iran & 804 & 1536 & 927 \\
\hline Pakistan & $1.8 \%$ & $1.4 \%$ & $13.0 \%$ & Japan & 787 & 1634 & 800 \\
\hline Israel & $1.7 \%$ & $1.6 \%$ & $24.5 \%$ & South Korea & 539 & 1656 & 5466 \\
\hline World Average & $0.8 \%$ & $0.8 \%$ & $8.8 \%$ & Total & 50,003 & 32,452 & 87,806 \\
\hline
\end{tabular}

Notes: Immigration response estimations test immigration responses of quotas-constrained countries to the 1990 Act by occupation. US permanent residency admissions are regressed on each country's 1983-1990 occupation admissions divided by the theoretical country-employment limit interacted with an indicator variable for post the 1990 Act's effective date. Regressions include country and year effects, cluster standard errors at the country level, and exclude Hong Kong due to its special US immigration treatment. The 1983-1990 quota shares are documented in the bottom-left panel for major countries; the bottom-right panel documents INS waiting list records close to the October 1991 effective date of the 1990 Act.

Patent regressions test US ethnic invention responses to 1990 Act. Ethnic patenting is regressed on the constructed immigration quotas estimators.

Regressions include country-year and industry-year effects; standard errors are clustered at the ethnicity level. 
Table 10A: Quotas Levels Specification

\begin{tabular}{|c|c|c|c|}
\hline & $\begin{array}{c}\text { No } \\
\text { Weights }\end{array}$ & $\begin{array}{c}\text { Patent } \\
\text { Weights }\end{array}$ & $\begin{array}{c}\text { Output } \\
\text { Weights }\end{array}$ \\
\hline & $(1)$ & $(2)$ & (3) \\
\hline & \multicolumn{3}{|c|}{ A. Log Foreign Output } \\
\hline Log US Immigration & 0.360 & 0.419 & 0.368 \\
\hline Quotas Estimator & $(0.193)$ & $(0.284)$ & $(0.225)$ \\
\hline \multirow[t]{2}{*}{ Observations } & 9912 & 9912 & 9912 \\
\hline & \multicolumn{3}{|c|}{ B. Log Foreign Labor Productivity } \\
\hline Log US Immigration & -0.024 & 0.039 & 0.011 \\
\hline Quotas Estimator & $(0.202)$ & $(0.220)$ & $(0.200)$ \\
\hline \multirow[t]{2}{*}{ Observations } & 9912 & 9912 & 9912 \\
\hline & \multicolumn{3}{|c|}{ C. Log Foreign Employment } \\
\hline Log US Immigration & 0.384 & 0.380 & 0.357 \\
\hline Quotas Estimator & $(0.120)$ & $(0.159)$ & $(0.125)$ \\
\hline Observations & 9912 & 9912 & 9912 \\
\hline
\end{tabular}

Notes: Row titles document the dependent variable studied; column titles document the weighting scheme employed. Panel estimations consider countryindustry observations taken from the 1985-1997 UNIDO manufacturing database Log US Immigration Quotas Estimators are developed from quotas changes due to the 1990 Act. Regressions include industry-year and country-industry fixed effects. Standard errors are clustered at the ethnicity level.
Table 10B: Quotas First-Differences Specification

\begin{tabular}{lccc}
\hline & $\begin{array}{c}\text { No } \\
\text { Weights }\end{array}$ & $\begin{array}{c}\text { Patent } \\
\text { Weights }\end{array}$ & $\begin{array}{c}\text { Output } \\
\text { Weights }\end{array}$ \\
\cline { 2 - 4 } & \multicolumn{3}{c}{ A. $\Delta$ Log Foreign Output } \\
\hline \multirow{2}{*}{$\Delta$ Log US Immigration } & 0.294 & 0.370 & 0.320 \\
Quotas Estimator & $(0.064)$ & $(0.090)$ & $(0.078)$ \\
Observations & 8736 & 8736 & 8736 \\
& B. $\Delta$ Log Foreign Labor Productivity \\
$\Delta$ Log US Immigration & 0.054 & 0.135 & 0.086 \\
Quotas Estimator & $(0.072)$ & $(0.074)$ & $(0.076)$ \\
Observations & 8736 & 8736 & 8736 \\
& C. $\Delta$ Log Foreign Employment \\
$\Delta$ Log US Immigration & 0.240 & 0.236 & 0.234 \\
Quotas Estimator & $(0.043)$ & $(0.070)$ & $(0.042)$ \\
Observations & 8736 & 8736 & 8736 \\
\hline
\end{tabular}

Notes: Row titles document the dependent variable studied; column titles document the weighting scheme employed. Panel estimations consider countryindustry observations taken from the 1985-1997 UNIDO manufacturing database. Log US Immigration Quotas Estimators are developed from quotas changes due to the 1990 Act. Regressions include industry-year fixed effects. Standard errors are clustered at the ethnicity level. 
Table 11A: Quotas Country Controls - Levels

\begin{tabular}{ccc}
$\begin{array}{c}\text { No } \\
\text { Weights }\end{array}$ & $\begin{array}{c}\text { Patent } \\
\text { Weights }\end{array}$ & $\begin{array}{c}\text { Output } \\
\text { Weights }\end{array}$ \\
\hline$(1)$ & $(2)$ & $(3)$ \\
\hline
\end{tabular}

A. Base Foreign Output Regression

Log US Immigration

Quotas Estimator

0.360

$(0.193)$

0.419

0.368

Observations

9912

9912

$(0.225)$

B. Including Foreign Ph.D.s in US

Log US Immigration

Quotas Estimator

0.335

(0.170)

0.362

(0.313)

0.317

Log Foreign Ph.D.

0.012

0.131

$(0.225)$

Students in US

(0.094)

(0.104)

0.085

8914

8914

$(0.105)$

8914

C. Excluding Mainland China

Log US Immigration

$$
0.335
$$

(0.228)

0.418

(0.342)

0.358

9653

9653

$(0.267)$

Observations

Log US Immigration

Quotas Estimator

D. Including Ethnic Time Trend

Observations

$\begin{array}{ccc}0.244 & 0.172 & 0.139 \\ (0.133) & (0.094) & (0.116) \\ 9912 & 9912 & 9912\end{array}$

Notes: See Table 10A. Panel A replicates the foreign country-industry output regressions (levels) from Table 10A. Panels B through D incorporate the country year controls indicated by the row titles. Regressions also maintain industry-year and country-industry fixed effects.
Table 11B: Quotas Country Controls - First-Differences

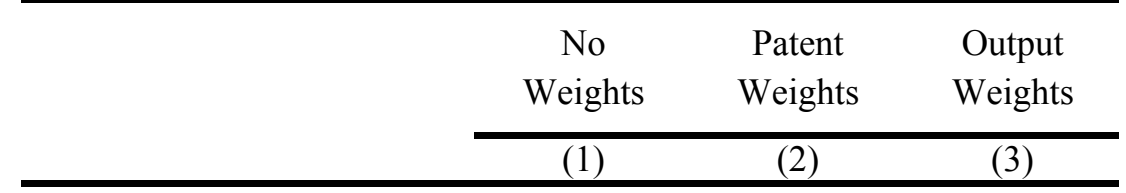

A. Base Foreign Output Regression

$\Delta$ Log US Immigration

Quotas Estimator

$\begin{array}{lll}0.294 & 0.370 & 0.320\end{array}$

$\begin{array}{lll}(0.064) & (0.090) & (0.078)\end{array}$

Observations

$8736 \quad 8736 \quad 8736$

B. Including Foreign Ph.D.s in US

$\Delta$ Log US Immigration

Quotas Estimator

$\begin{array}{lll}0.280 & 0.350 & 0.297\end{array}$

$\begin{array}{lll}(0.058) & (0.112) & (0.079)\end{array}$

$\Delta$ Log Foreign Ph.D.

$\begin{array}{lll}0.033 & 0.054 & 0.054\end{array}$

Students in US

(0.069)

(0.090)

(0.078)

Observations

7780

7780

7780

C. Excluding Mainland China

$\begin{array}{lccc}\Delta \text { Log US Immigration } & 0.210 & 0.306 & 0.252 \\ \text { Quotas Estimator } & (0.113) & (0.149) & (0.128) \\ \text { Observations } & 8518 & 8518 & 8518\end{array}$

D. Including Ethnic Time Trend

$\begin{array}{lccc}\Delta \text { Log US Immigration } & 0.183 & 0.202 & 0.172 \\ \text { Quotas Estimator } & (0.132) & (0.117) & (0.131) \\ \text { Observations } & 8736 & 8736 & 8736\end{array}$

Notes: See Table 10B. Panel A replicates the foreign country-industry output regressions (first-differences) from Table 10B. Panels B through D incorporate the country-year controls indicated by the row titles. Regressions also maintain industry-year fixed effects. 
Table 12A: Quotas Falsifications - Levels

\begin{tabular}{ccc}
$\begin{array}{c}\text { No } \\
\text { Weights }\end{array}$ & $\begin{array}{c}\text { Patent } \\
\text { Weights }\end{array}$ & $\begin{array}{c}\text { Output } \\
\text { Weights }\end{array}$ \\
\hline$(1)$ & $(2)$ & $(3)$ \\
\hline
\end{tabular}

A. Base Foreign Output Regression

Log US Immigration

$\begin{array}{lll}0.360 & 0.419 & 0.368\end{array}$

Quotas Estimator

(0.193)

$(0.284)$

$(0.225)$

Observations

9912

9912

9912

B. Including 1987 Counterfactual

Log US Immigration

$\begin{array}{lll}0.222 & 0.265 & 0.220\end{array}$

Quotas Estimator

$(0.100)$

$(0.119)$

$(0.105)$

1987 Counterfactual

0.206

0.231

Quotas Estimator

(0.213)

$(0.276)$

0.221

Observations

9912

9912

$(0.243)$

C. Including 1995 Counterfactual

\section{Log US Immigration}

Quotas Estimator

1995 Counterfactual

Quotas Estimator

$\begin{array}{ccc}0.347 & 0.514 & 0.409 \\ (0.261) & (0.399) & (0.311) \\ 0.036 & -0.260 & -0.113 \\ (0.201) & (0.327) & (0.246)\end{array}$

Observations

9912

9912

9912

Notes: See Table 10A. Panel A replicates the foreign country-industry output regressions (levels) from Table 10A. Panels B and C incorporate counterfactuals moving the 1990 Act's effective date of 1991 forward to 1987 and back to 1995.

Regressions also maintain industry-year and country-industry fixed effects.
Table 12B: Quotas Falsifications - First-Differences

\begin{tabular}{ccc}
$\begin{array}{c}\text { No } \\
\text { Weights }\end{array}$ & $\begin{array}{c}\text { Patent } \\
\text { Weights }\end{array}$ & $\begin{array}{c}\text { Output } \\
\text { Weights }\end{array}$ \\
\hline$(1)$ & $(2)$ & $(3)$ \\
\hline
\end{tabular}

A. Base Foreign Output Regression

$\Delta$ Log US Immigration

$\begin{array}{ccc}0.294 & 0.370 & 0.320 \\ (0.064) & (0.090) & (0.078) \\ 8736 & 8736 & 8736\end{array}$

Observations

B. Including 1987 Counterfactual

$\begin{array}{lccc}\Delta \text { Log US Immigration } & 0.262 & 0.335 & 0.287 \\ \text { Quotas Estimator } & (0.061) & (0.071) & (0.069) \\ \Delta 1987 \text { Counterfactual } & 0.296 & 0.326 & 0.311 \\ \text { Quotas Estimator } & (0.182) & (0.226) & (0.205) \\ \text { Observations } & 8736 & 8736 & 8736\end{array}$

C. Including 1995 Counterfactual

$\begin{array}{lccc}\Delta \text { Log US Immigration } & 0.266 & 0.439 & 0.345 \\ \text { Quotas Estimator } & (0.079) & (0.102) & (0.076) \\ \Delta 1995 \text { Counterfactual } & 0.069 & -0.170 & -0.063 \\ \text { Quotas Estimator } & (0.154) & (0.099) & (0.118)\end{array}$

Observations

8736

8736

8736

Notes: See Table 10B. Panel A replicates the foreign country-industry output regressions (first-differences) from Table 10B. Panels B and C incorporate counterfactuals moving the 1990 Act's effective date of 1991 forward to 1987 and back to 1995 . Regressions also maintain industry-year fixed effects. 